Article

\title{
Fatigue Cracking of Additively Manufactured Materials-Process and Material Perspectives
}

\author{
Torsten Fischer ${ }^{1, *}\left(\mathbb{C}\right.$, Bernd Kuhn $^{1}\left(\mathbb{D}\right.$, Detlef Rieck ${ }^{2}$, Axel Schulz ${ }^{3}$, Ralf Trieglaff ${ }^{3}$ and \\ Markus Benjamin Wilms ${ }^{4}$ \\ 1 Institute of Energy and Climate Research (IEK), Microstructure and Properties of Materials (IEK-2), \\ Forschungszentrum Jülich GmbH, 52425 Jülich, Germany; b.kuhn@fz-juelich.de \\ 2 ENCOS GmbH \& Co. KG, 17489 Greifswald, Germany; drieck@encos.de \\ 3 TÜV NORD EnSys GmbH \& Co. KG, 22525 Hamburg, Germany; aschulz@tuev-nord.de (A.S.); \\ rtrieglaff@tuev-nord.de (R.T.) \\ 4 Fraunhofer-Institute for Laser Technology (ILT), 52074 Aachen, Germany; \\ markus.benjamin.wilms@ilt.fraunhofer.de \\ * Correspondence: t.fischer@fz-juelich.de; Tel.: +49-2461-61-5096
}

Received: 23 July 2020; Accepted: 5 August 2020; Published: 11 August 2020

Featured Application: Improved utilization of inherent lifetime of conventionally and additively manufactured commercial materials; replacement of austenitic and/or Duplex stainless steels by novel, lower cost ferritic (HiperFer) steels in (petro)chemical and power engineering; material, component, and manufacturing process design for increased safety margins of AM materials.

\begin{abstract}
Strong efforts are made internationally to optimize the process control of laser additive manufacturing processes. For this purpose, advanced detectors and monitoring software are being developed to control the quality of production. However, commercial suppliers of metal powders and part manufacturers are essentially focused on well-established materials. This article demonstrates the potential of optimized process control. Furthermore, we outline the development of a new high temperature structural steel, tailored to best utilize the advantages of additive manufacturing techniques. In this context, the impact of production-induced porosity on fatigue strength of austenitic 316L is presented. Additionally, we discuss the first conceptual results of a novel ferritic steel, named HiperFer (High Performance Ferrite), which was designed for increased fatigue strength. This ferritic, Laves phase-strengthened, stainless steel could be used for a wide range of structural components in power and (petro)chemical engineering at maximum temperatures ranging from about 580 to $650{ }^{\circ} \mathrm{C}$. This material benefits from in situ heat treatment and counteracts process-related defects by "reactive" crack obstruction mechanisms, hampering both crack initiation and crack propagation. In this way, increased fatigue resistance and safety can be achieved.
\end{abstract}

Keywords: additive manufacturing (AM); selective laser melting (SLM); laser powder bed fusion (LPBF); laser metal deposition (LMD); 316L; HiperFer; fatigue crack growth (FCG); pores; residual fatigue lifetime

\section{Introduction}

Additive manufacturing (AM) is a relatively new innovative processing technology with exceptionally high design freedom that cannot be achieved with conventional manufacturing methods. Components can be manufactured directly from CAD (computer aided design) models. Due to layered build-up of the component, sophisticated geometries such as complex inner cooling structures in thermally loaded components or local modification of the materials can be implemented. These features 
make them particularly interesting for applications in power engineering. Residual porosity of the products after manufacturing is a significant impact factor on the mechanical-technological properties of additively manufactured components. This may affect the mechanical properties, especially fatigue and fracture behavior of the final structures. In fact, pores [1-4] and resulting notch effects [2,4-6] are considered to be the main reason for the lower fatigue strength of additively manufactured materials in comparison to conventionally produced materials.

The application of fracture mechanics-based damage tolerance concepts in condition assessment during the service life of components has been evaluated and regulated over many years in various industries such as aviation [7], nuclear [8], pressure vessel technology [9], and offshore wind power [10]. Ideally, these concepts should already be implemented in the design and manufacturing phase for strength and service life evaluation. For the application of fracture mechanics concepts including the damage tolerance concept, knowledge not only of the strength parameters but also of the crack propagation parameters are necessary. This is reflected in a series of publications on the experimental investigation of crack propagation parameters of laser powder bed fusion (LPBF)-manufactured, austenitic 316 steel specimens $[1,11,12]$. 316 L was chosen because it is a commonly used steel grade with a wide range of applications (process, food, power conversion, etc.) and good powder availability. The fatigue crack propagation rates in all the three build directions (XY, ZX, ZY) of LPBF-manufactured 316L were found to be higher compared to wrought material [1]. This was attributed to the porosity of the LPBF manufactured material.

For this reason, fatigue crack growth experiments were carried out on LPBF-manufactured 316L specimens, produced with process parameters according to the current state of technology. The experiments were accompanied by extensive microstructure investigations of the tested specimens. In addition, an advanced strategy will be presented to ensure safe application of AM-processed, pore-containing materials - in most cases, materials established in the market (e.g., 316L stainless steel) are applied in additive manufacturing processes and efforts are made to optimize the process towards reduced component porosity. Safe application of AM-manufactured components necessitates careful non-destructive porosity inspection and implementation in adapted lifetime models, such as those outlined in the following.

In addition to this, we present a tailor-made material based on HiperFer [13-19] for additive manufacturing, which (i) develops its full performance potential in being processed by additive manufacturing (e.g., in situ heat treatment, high cooling rate, tailored microstructure) and (ii) counteracts probable process-related flaws by "active" crack-obstructing mechanisms (e.g., thermomechanically induced precipitation and sub-grain formation, such as that outlined in [18]).

Furthermore, this paper demonstrates the implementation of the porosity aspect into fracture mechanics-based damage tolerance analysis for the design and manufacturing process of additively manufactured steel components. Using an additive manufactured downscaled pressure vessel model, the pore density was analyzed by means of computer tomography and the stress distribution was calculated on the basis of pore position in critical design areas of the component. Subsequently, the impact on crack propagation behavior and lifetime was investigated.

\section{Materials and Methods}

\subsection{Test Components and Pore Density Evaluation}

The pore density of a downscaled pressure vessel model component was investigated. For this purpose, a component design was developed, and two test components were LPBF-manufactured simultaneously. Figure 1 depicts a technical drawing of the experimental component.

The experimental pressure vessel models consisted of cylindrical bodies with a diameter of $76.2 \mathrm{~mm}$, a flat bottom, a $45^{\circ}$ (axially inclining) nozzle, and a conical transition to the upper nozzle. This test carrier was developed and manufactured especially for evaluation of AM-related pore formation in bursting tests for materials applied in gas pipelines. Austenitic 1.4404 (316L) powder 
material (cf. Section 2.2) was used for manufacturing via LPBF. Subsequently, the components were computer tomographed by utilizing a YXLON CT System "Modular". Pore density was evaluated by applying the software VolumeGraphics 3.0. The specimens were fixed in low-density styrofoam holders during tomography. All pores larger than $0.08 \mathrm{~mm}^{3}$ could be detected with this setup. In addition, a software-based method for pore evaluation in additively manufactured components was developed. For this purpose, the measured pores were idealized by spheres of equal volumes and then automatically subtracted from the base body volume. This method enables simple meshing and computation in established finite element analysis (FEA) software.

On the basis of the model pressure vessel presented here, we developed a detailed study that investigated how the experimentally determined crack propagation rates potentially affected growth of a postulated initial starter crack ( $2 \mathrm{~mm}$ depth).

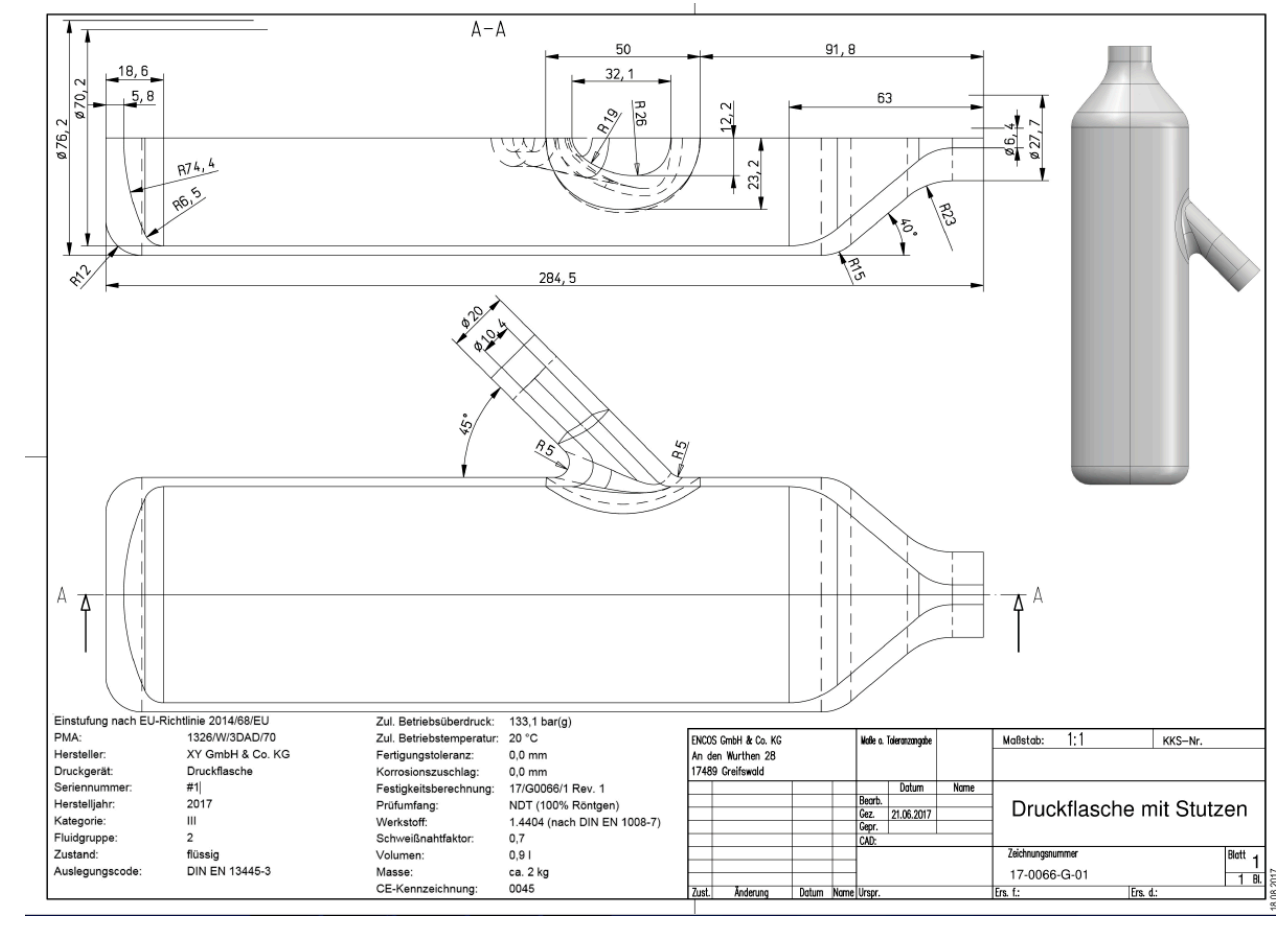

Figure 1. Technical drawing of the experimental pressure vessel model [20].

\subsection{Conventionally and LPBF-Manufactured 316L Materials}

Conventionally manufactured austenitic stainless steel AISI 316L (1.4404) sheet metal $(20 \times 500 \times$ $500 \mathrm{~mm}$ ) from Thyssenkrupp Schulte $\mathrm{GmbH}$, Düsseldorf, Germany, was used for comparison with the additively manufactured material. The chemical composition is given in Table 1. Laser powder bed fusion by an SLM280 HL (SLM Solutions Group AG, Lübeck, Germany) machine was chosen in terms of the commercial 316L material. The model pressure vessels and fatigue testing specimens were manufactured by Rolf Lenk Werkzeug $\mathrm{u}$. Maschinenbau $\mathrm{GmbH}$ in Ahrensburg, Germany. The process parameters are given in Table 2.

Table 1. Chemical compositions of the austenitic 316L sheet metal and powder materials (wt.-\%).

\begin{tabular}{cccccccccccc}
\hline & $\mathbf{F e}$ & $\mathbf{C}$ & $\mathbf{S i}$ & $\mathbf{M n}$ & $\mathbf{P}$ & $\mathbf{S}$ & $\mathbf{C r}$ & $\mathbf{N i}$ & $\mathbf{M o}$ & $\mathbf{N}$ & $\mathbf{C u}$ \\
\hline 316L sheet metal & Balance & 0.015 & 0.470 & 1.26 & 0.027 & 0.001 & 16.8 & 10.10 & 2.14 & 0.04 & 0.064 \\
316L powder & Balance & 0.02 & 0.67 & 1.16 & 0.022 & 0.006 & 17.13 & 10.92 & 2.33 & 0.1 & - \\
\hline
\end{tabular}


Table 2. Laser powder bed fusion (LPBF) process parameters.

\begin{tabular}{cc}
\hline Parameter: & Value: \\
\hline Layer thickness & $50 \mu \mathrm{m}$ \\
Laser power & $275 \mathrm{~W}$ \\
Exposure strategy & Stripes \\
Scan velocity & $760 \mathrm{~mm} / \mathrm{s}$ \\
Hatch distance & $0.12 \mathrm{~mm}$ \\
Volume energy density & $60.3 \mathrm{~J} / \mathrm{mm}^{3}$ \\
Build rate & $13.5 \mathrm{~cm}^{3} / \mathrm{h}$ \\
\hline
\end{tabular}

316L powder material (particle size distribution: $10-45 \mu \mathrm{m}$, spherical morphology; supplied by SLM Solutions Group AG, Lübeck, Germany) was used for manufacturing the semi-finished samples (Figure 2a). The chemical analysis of the powder material is displayed in Table 1.
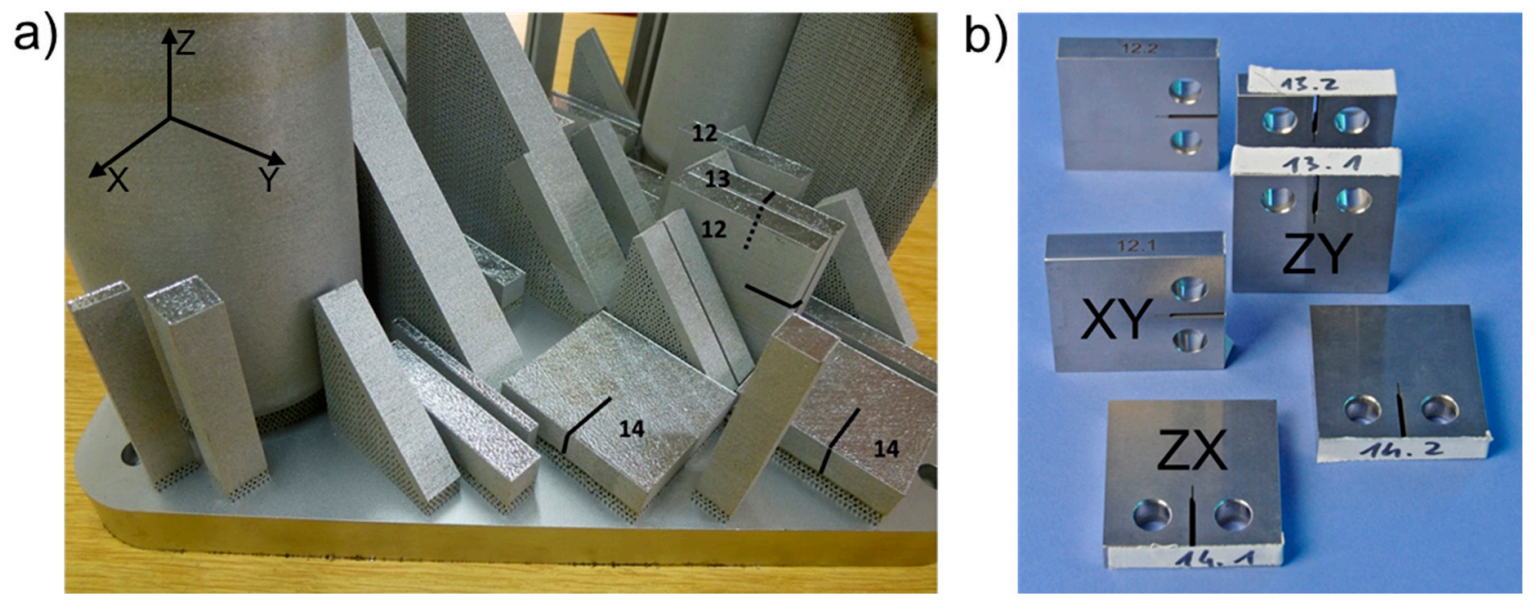

Figure 2. (a) Semi-finished LPBF manufactured samples and (b) final compact tension specimens after electrical discharge machining (EDM).

The final compact tension (CT) specimen geometry (Figure $2 b$ ) was produced by electrical discharge machining (EDM) from the semi-finished samples produced by LPBF (Figure 2a). A CT specimen geometry with a width of $W=40 \mathrm{~mm}$, thickness of $B=10 \mathrm{~mm}$, and an initial notch depth of $\mathrm{a}_{0}=10 \mathrm{~mm}$ in accordance with the ASTM testing standard [21] was applied in the experimental program. The same geometry was used for the conventionally produced CT specimens.

\subsection{Conventionally and LMD-Manufactured Laves Phase Strengthened Ferritic Steel Materials}

In order to demonstrate the alloy development progress of HiperFer/ HiperFerAM (Additive Manufacturing), we also investigated the predecessor alloy Crofer $22 \mathrm{H}$. The conventional HiperFer material was vacuum induction melted by the Steel Institute of RWTH Aachen University, Germany. The ingots were hot rolled to $16 \mathrm{~mm}$ thickness at $920{ }^{\circ} \mathrm{C}$ and subsequently precipitation annealed $\left(0.5-10 \mathrm{~h} / 600-650^{\circ} \mathrm{C}\right)$. Detailed information on the HiperFer steel grade is given in [18]. Conventionally manufactured Crofer22 $\mathrm{H}$ was supplied by VDM Metals $\mathrm{GmbH}$, Unna, Germany. Crofer22 H [22-24] was recrystallized and additionally precipitation annealed at $0.5-10 \mathrm{~h}$ in the temperature range of 600 to $650^{\circ} \mathrm{C}$. The chemical compositions of conventional/LMD (laser metal deposition)-manufactured HiperFer/HiperFer ${ }^{\mathrm{AM}}$ are given in Table 3. The base HiperFer ${ }^{\mathrm{AM}}$ powder material was produced via gas atomization of an alloyed high purity $\mathrm{Fe} 22 \mathrm{Cr}$ alloy with argon gas. Elemental, high purity $\mathrm{Si}, \mathrm{Nb}$, and $\mathrm{W}$ powder materials were added to the $\mathrm{Fe} 22 \mathrm{Cr}$ powder and blended by mixing in a tubular mixing device (WAB $\mathrm{GmbH}$ ) for $30 \mathrm{~min}$ by Fraunhofer ILT, Aachen, Germany. 
Table 3. Chemical compositions of the ferritic steels (wt.-\%).

\begin{tabular}{|c|c|c|c|c|c|c|c|c|c|}
\hline \multirow{4}{*}{ Crofer22 H } & $\mathrm{C}$ & $\mathrm{S}$ & $\mathbf{N}$ & $\mathrm{Cr}$ & $\mathrm{Ni}$ & Mn & $\mathrm{Si}$ & Mo & $\mathrm{Ti}$ \\
\hline & 0.009 & 0.002 & 0.02 & 22.8 & 0.27 & 0.45 & 0.31 & 0.01 & 0.06 \\
\hline & $\mathrm{Nb}$ & W & $\mathrm{Cu}$ & $\mathrm{Fe}$ & $\mathbf{P}$ & $\mathrm{Al}$ & $\mathrm{Mg}$ & Co & La \\
\hline & 0.52 & 2.11 & 0.02 & Balance & 0.017 & 0.015 & $<0.01$ & 0.01 & 0.05 \\
\hline \multirow{4}{*}{$\begin{array}{l}\text { HiperFer } \\
\text { 17Cr2 }\end{array}$} & C & $S$ & $\mathbf{N}$ & $\mathrm{Cr}$ & $\mathbf{N i}$ & Mn & Si & Mo & $\mathrm{Ti}$ \\
\hline & $<0.003$ & $<0.001$ & $<0.003$ & $17-18$ & - & $0.2-0.5$ & $0.2-0.3$ & - & - \\
\hline & $\mathrm{Nb}$ & $\mathbf{W}$ & $\mathrm{Cu}$ & $\mathrm{Fe}$ & $\mathbf{P}$ & Al & $\mathrm{Mg}$ & Co & La \\
\hline & $0.5-0.6$ & $2.4-2.6$ & - & Balance & - & - & - & - & - \\
\hline \multirow{4}{*}{ HiperFer $^{\mathrm{AM}}$} & $\mathrm{C}$ & $S$ & $\mathbf{N}$ & $\mathrm{Cr}$ & $\mathrm{Ni}$ & Mn & $\mathrm{Si}$ & Mo & $\mathrm{Ti}$ \\
\hline & $<0.003$ & $<0.001$ & $<0.003$ & 22 & - & $0.2-0.5$ & 1 & - & - \\
\hline & $\mathrm{Nb}$ & W & $\mathrm{Cu}$ & $\mathrm{Fe}$ & $\mathbf{P}$ & Al & Mg & Co & La \\
\hline & 1.5 & 2 & - & Balance & - & - & - & - & - \\
\hline
\end{tabular}

${ }^{*}[25]$.

The experimental HiperFer ${ }^{\mathrm{AM}}$ alloy was deposited on a steel substrate (AISI H10, 1.2365) by Fraunhofer ILT utilizing laser metal deposition. Specimens were manufactured on two five-axis handling systems, equipped with fiber-coupled diode laser systems LDM3000-60 (emitted wavelength: $976 \mathrm{~nm}$; beam parameter product (BPP): $60 \mathrm{~mm} \times \mathrm{mrad}$ ) and LDF2000-30 (emitted wavelengths 1025, $1064 \mathrm{~nm}$; BPP: $30 \mathrm{~mm} * \mathrm{mrad}$ ) (Laserline GmbH, Mülheim-Kärlich, Germany). For both machines, the optical alignment systems consisted of optical fibers with a core diameter of $600 \mu \mathrm{m}$. For $3 \mathrm{~mm}$ beam diameter, a collimation lens $\left(f_{c}, 3 \mathrm{~mm}=65 \mathrm{~mm}\right)$, followed by a focusing lens $\left(f_{f}, 3 \mathrm{~mm}=230 \mathrm{~mm}\right)$ was applied. The smaller, $0.66 \mathrm{~mm}$ beam diameter was achieved via a combination of a collimation $\left(f_{c}, 0.66 \mathrm{~mm}=200 \mathrm{~mm}\right)$ and a focusing lens $\left(f_{f}, 0.66 \mathrm{~mm}=182 \mathrm{~mm}\right)$. The powder material was fed by pure argon carrier gas via a disc-based feeding system (Sulzer-Metco Twin 10C, OC Oerlikon AG, Pfäffikon, Switzerland) through a coaxial three-jet nozzle (Fraunhofer ILT). Shielding of the melt pool was achieved by argon shielding gas fed through the coaxial nozzle. The HiperFer ${ }^{\mathrm{AM}}$ powder mixture was processed through applying the parameters listed in Table 4.

Table 4. HiperFer ${ }^{\mathrm{AM}}$ laser metal deposition (LMD) process parameters.

\begin{tabular}{|c|c|c|}
\hline Process Parameter & Value (3 mm Beam Diameter) & Value (0.66 mm Beam Diameter) \\
\hline Laser power & $1375 \mathrm{~W}$ & $360 \mathrm{~W}$ \\
\hline Feed speed & $400 \mathrm{~mm} / \mathrm{min}$ & $1500 \mathrm{~mm} / \mathrm{min}$ \\
\hline Powder mass flow rate & $11.3 \mathrm{~g} / \mathrm{min}$ & $2.4 \mathrm{~g} / \mathrm{min}$ \\
\hline Track offset & $2.3 \mathrm{~mm}$ & $0.35 \mathrm{~mm}$ \\
\hline Height offset & $1.4 \mathrm{~mm}$ & $0.3 \mathrm{~mm}$ \\
\hline Beam diameter & $3 \mathrm{~mm}$ & $0.66 \mathrm{~mm}$ \\
\hline Deposition strategy & Unidirectional & Unidirectional \\
\hline Nozzle type & Three-jet nozzle & Three-jet nozzle \\
\hline Shielding gas & Argon & Argon \\
\hline
\end{tabular}

\subsection{Thermomechanical Fatigue Experiments}

Out-of-phase (oop) thermomechanical fatigue (TMF) experiments were conducted in total strain control in a temperature range of 50 to $650{ }^{\circ} \mathrm{C}$. The specimens were inductively heated. Type $\mathrm{R}$ sling thermocouples were installed at the gauge length of the specimens to monitor gauge temperature. Strain measurement was accomplished by high temperature extensometers directly attached to the gauge proportions. The specimens were both heated and cooled with a rate of $\mathrm{dT} / \mathrm{dt}=10 \mathrm{Ks}^{-1}$. Below $200{ }^{\circ} \mathrm{C}$ the cooling rate was limited and accordingly the cooling half cycle duration was approximately $85 \mathrm{~s}$. Furthermore, no hold times were implemented at the hot ends of the cycles to reduce the influence of creep to a minimum. 


\subsection{Fatigue Crack Growth Experiments}

Fatigue crack growth (FCG) experiments were performed in a servo hydraulic testing machine (Instron Model 1343). In this test set-up the specimens were inductively heated. Before testing, the CT samples were pre-cracked to a starter crack length to width ratio $(\mathrm{a} / \mathrm{W})$ of about 0.4 by cyclic loading at ambient temperature in an Instron Model 1603 resonance tester. The direct current potential drop (PD) technique was used to monitor crack length during the FCG experiments. Furthermore, FCG experiments were conducted through applying a sinusoidal waveform at constant load ratio $(\mathrm{R}=$ $0.1)$ until the termination criterion $(\mathrm{a} / \mathrm{W}=0.7)$ was reached. The cyclic stress intensity factor $\Delta \mathrm{K}$ was determined according to ASTM E647 [21], and the evaluation of the cyclic crack propagation rate was accomplished by a seven-point polynomial method according to ASTM E647 [21]. The performed experiments are summarized in Table 5.

Table 5. Detailed test matrix of the fatigue crack growth (FCG) experiments.

\begin{tabular}{|c|c|c|}
\hline Material & Temperatures & Number of $F_{C G}$ Air Tests $(R=0.1, f=20 \mathrm{~Hz})$ \\
\hline AM316L-XY & RT & 2 \\
\hline AM316L-ZY & RT & 2 \\
\hline AM316L-ZX & RT & 2 \\
\hline 316L (conventional) & $\mathrm{RT} / 650^{\circ} \mathrm{C}$ & $2 / 1$ \\
\hline Crofer22 H, PA & RT & 1 \\
\hline HiperFer 17Cr2, PA & $650^{\circ} \mathrm{C}$ & 1 \\
\hline
\end{tabular}

\subsection{Microstructure Investigation}

Subsequent to the FCG experiments, the fracture surfaces (excluding the pre-crack and residual fracture surface) were cut from the CT specimens for examination of longitudinal sections. Therefore, the specimens were cold embedded in epoxy resin under vacuum, and then ground, polished, and electrolytically etched in $\mathrm{H}_{2} \mathrm{SO}_{4}$.

The experimental HiperFer ${ }^{\mathrm{AM}}$ specimens were etched with V2A-etchant to achieve homogeneous overviews of the individual melt layers.

Light optical micrographs were taken using a Leica microscope (model MeF4). A Zeiss Merlin field emission scanning electron microscope (FESEM) was applied for high resolution microstructural investigation. For electron backscatter diffraction (EBSD) analysis, the samples were polished for 2-3 $\mathrm{h}$ to a sub-micron finish in colloidal silica suspension. The EBSD analysis was conducted at a Zeiss Merlin SEM, equipped with Oxford Instruments EBSD (NORD LYS 2 camera) and energy dispersive x-ray spectroscopy (edx) systems (X Max 150). The pore size was measured by utilizing the software package Olympus analySIS Pro 5.0.

\section{Results and Discussion}

\subsection{Pore Density Evaluation of the Model Pressure Vessel}

The results of the defect analysis via computer tomography are displayed in Figure 3. Distinct differences regarding pore distribution and the number of pores were encountered in the two model pressure vessels.

Although both vessels were produced in the same run, we encountered differences in pore distribution. A possible reason for this is the significant number of irregularly distributed accompanying samples on the installation space, which caused different laser dwell times.

The effect of pores on the total fatigue lifetime of a component was investigated in [20]. It was hypothesized that crack growth increases abruptly when a pore is reached, whereas crack growth is retarded subsequently because the crack must be initiated again.

Therefore, the number of cycles until re-initiation of crack growth determines whether further crack growth is accelerated or retarded. In this context, pore distribution in the component is decisive 
(near or far from the surface, see Figure 4). For this purpose, the impact of pores in an exemplary component section (transition region from the cylinder wall to the torispherical head) under internal pressure loading was evaluated first. This region is characterized by high tensile stresses at the inner surface and compressive stresses at the outer surface.

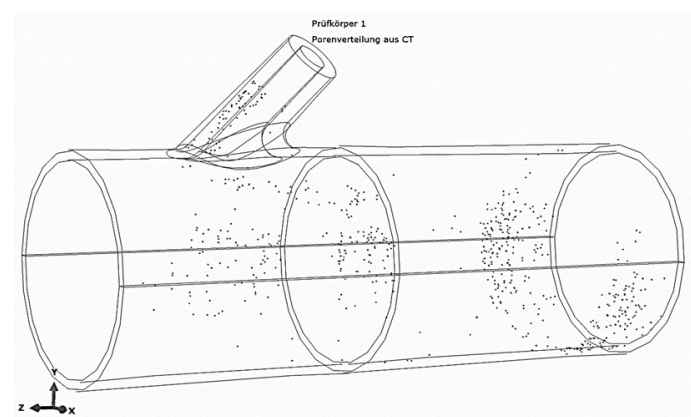

Pressure vessel 1

Total number of pores -620

Diameter of the largest pore- $449 \mu \mathrm{m}$

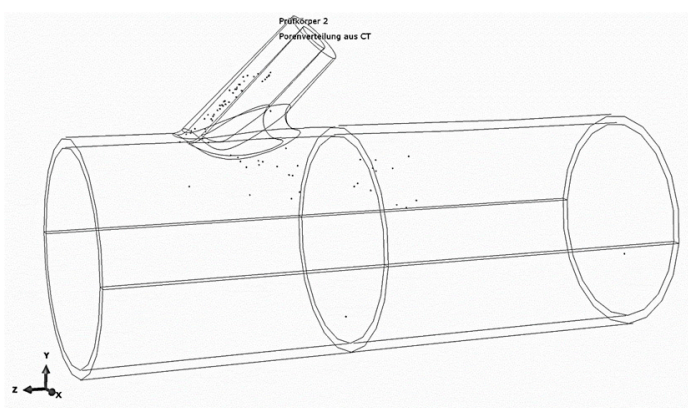

Pressure vessel 2

Total number of pores- 79

Diameter of the largest pore $-344 \mu \mathrm{m}$

Figure 3. Evaluation of pore distribution and size in the two additively manufactured model pressure vessels [20].

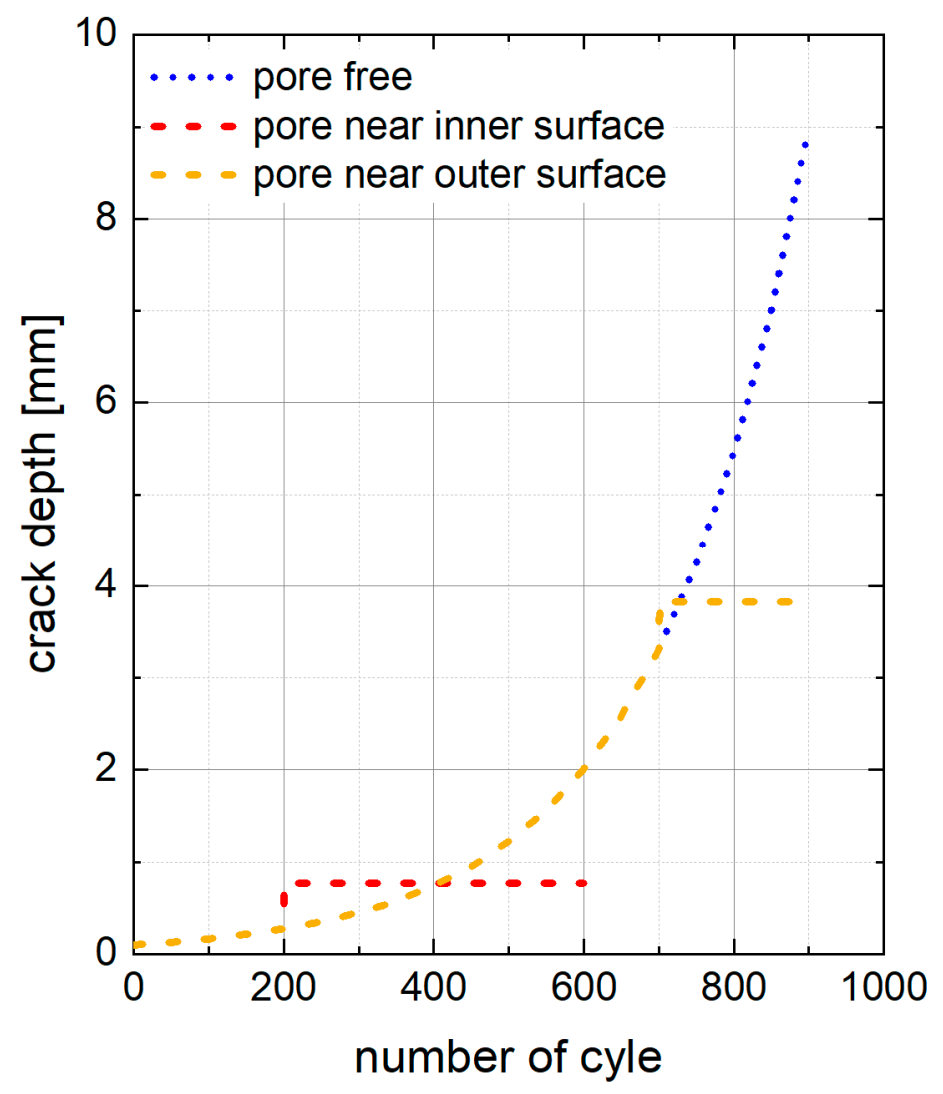

Figure 4. Working hypothesis for crack growth in structures with pores [20].

Therefore, three simple axially symmetric models were created using the measurement results from computer tomography (Figure 5). Model I is a non-porous basic model for comparison, and model II features a pore near the surface, i.e., in a critical design area of high tensile stress. Model III 
presents a pore near the outer surface, i.e., under compressive stress. The stress distributions in the component wall through the pore positions are illustrated in Figure 6.

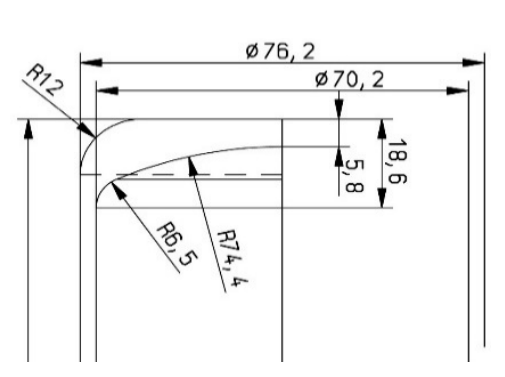

transition from wall to torispherical head

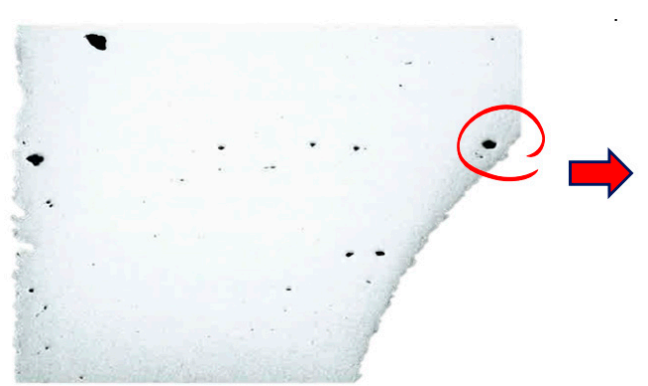

microstructure with pores

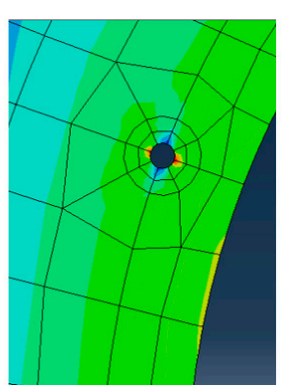

FEM model

Figure 5. Pore simulation based on computer tomography results [20].

a)
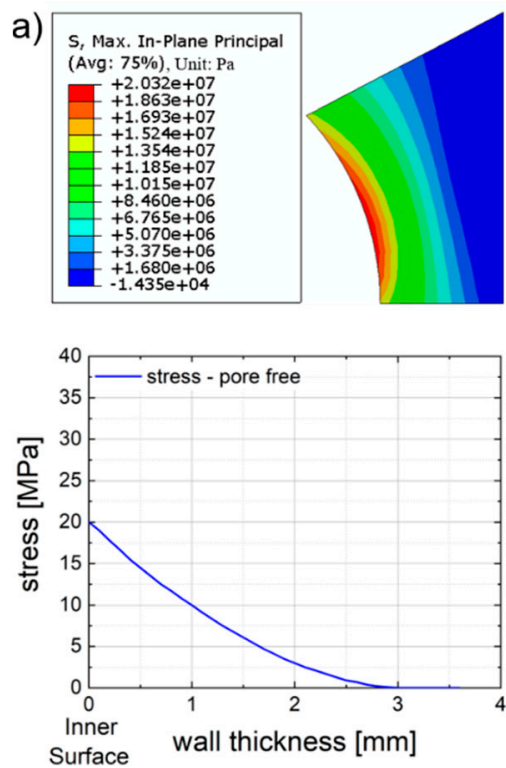
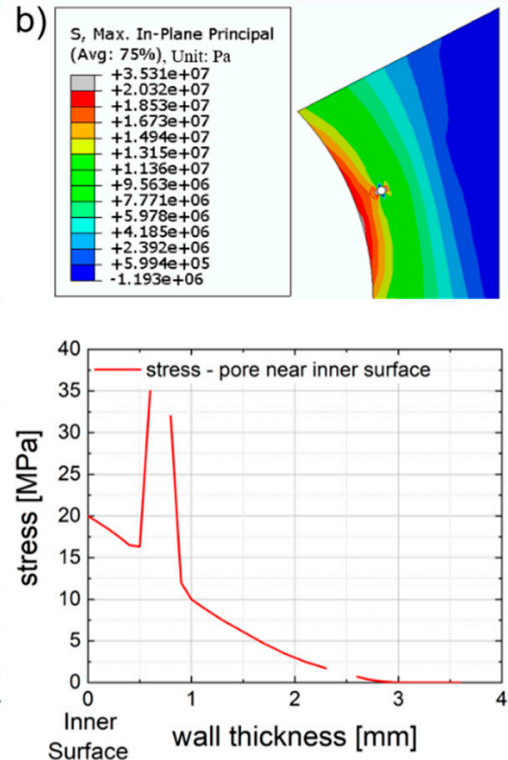
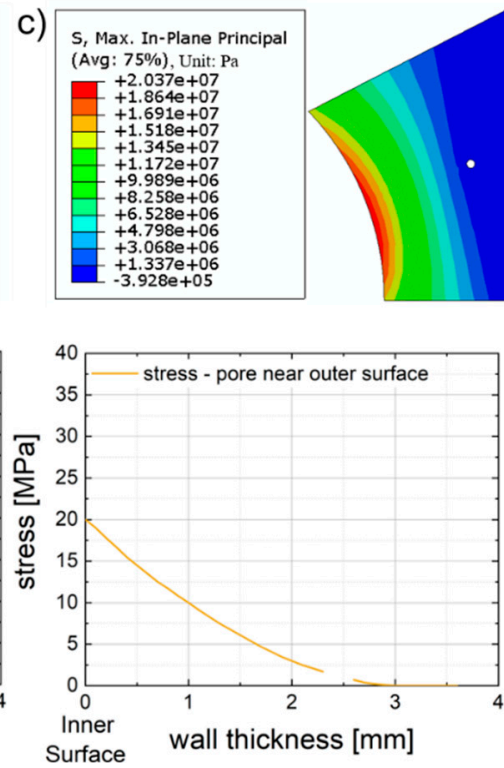

Figure 6. Stress distribution in (a) a pore free component, (b) a pore near the inner surface of the component, and (c) a pore near the outer surface of the component and through the wall (internal pressure 10 bar) [20].

An increase in stress at the pore edges only occurred if the pore was located in a critical design area of high stress concentration. In model II, representing a near-surface pore, significantly higher stresses occurred at the pore edges in comparison to the pore-free model I.

In the pore-free component (Figure 6a), the highest stresses appeared at the inner surface of the intersection. If there was a pore nearby (Figure 6b), the stresses at the pore edge were higher than at the inner surface. Therefore, the crack initiated from the pore. In the next step, the crack grew towards the highest stresses, which apart from the pore appeared at the inner surface. Only when the crack reached the inner surface did the crack growth direction turn from the pore towards the outer surface and the crack would grow into the depth of the wall [20].

The analysis showed that pores acted as notches in critical design regions and thus may act as crack initiators. A crack retarding effect, as originally assumed, did not exist. In this context, it should be noted that the pores were idealized as spheres of equivalent volume in the FEM analysis. In reality, the surfaces of the detected pores were irregular, sometimes sharp-edged, which may have had an effect on crack initiation properties. 
The fatigue analyses carried out showed that pores could significantly shorten the technical fatigue lifetime in areas of high stress. On the other hand, crack growth and thus residual lifetime itself was largely independent of the presence of pores. Small pore size caused only slightly accelerated crack growth. Consequently, crack growth corresponded approximately to that in a pore-free structure [20].

These results demonstrate the enormous importance of fatigue crack growth for the design and lifetime evaluation of additively manufactured components. A criterion for safe components has to be low crack propagation rate or high crack growth resistance. Therefore, materials with low fatigue crack growth rate are of central importance for the tolerance to manufacturing defects.

\subsection{Crack Propagation in Conventionally and Additively Manufactured $316 \mathrm{~L}$}

In additive manufacturing of components, process defects (like pores, which may lead to crack initiation) in critical design regions cannot be completely avoided. For this reason, the investigation of crack propagation behavior is a prerequisite for the safety of components, for instance, for energy conversion processes. Figure 7 shows a comparison of the crack growth behavior of the additively manufactured material in the different build directions in comparison to conventionally manufactured material.

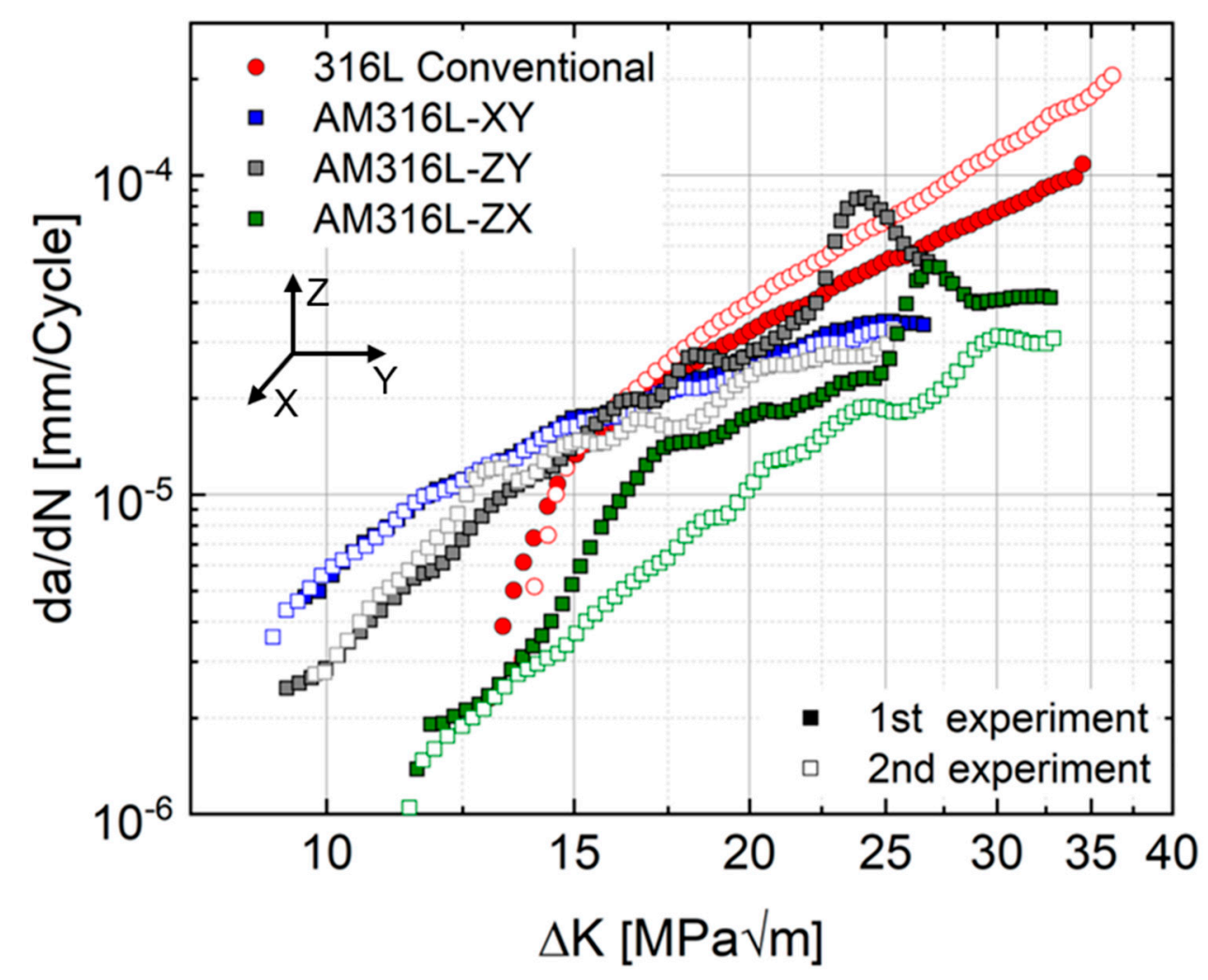

Figure 7. Crack growth in LPBF (three different build directions) and conventionally manufactured 316L at ambient temperature.

In all additively manufactured specimens, the crack propagation rates per cycle $(\mathrm{da} / \mathrm{dN})$ were lower, regardless of build direction, with the only exception of a small $\Delta \mathrm{K}$ range from $\approx 23-26 \mathrm{MPa} \sqrt{\mathrm{m}}$ in the first $\mathrm{ZY}$ specimen. The lowest $\mathrm{da} / \mathrm{dN}$ was measured at the specimen from the $\mathrm{ZX}$ direction. For a given value of $\Delta \mathrm{K}$, the crack propagation rate was up to eight times lower than in the conventionally produced material. Furthermore, the highest $\Delta \mathrm{K}$ value $(\approx 11.5 \mathrm{MPa} \sqrt{ } \mathrm{m})$ for initiation of crack propagation (note that this value is not a threshold value, i.e., crack growth can occur even below this value) of all the additively manufactured specimens was measured in the ZX samples, too. However, this $\Delta \mathrm{K}$ value for initiating crack propagation was about $2.3 \mathrm{MPa} \sqrt{ } \mathrm{m}$ lower compared to conventionally 
produced material. In the $X Y$ and $Z Y$ specimens, lower $\Delta K$ values for crack propagation initiation were encountered (in the $X Y$ specimen: $\Delta \mathrm{K} \approx 9.6 \mathrm{MPa} \sqrt{ } \mathrm{m}$, in the $\mathrm{ZY}$ specimen: $9.4 \mathrm{MPa} \sqrt{ } \mathrm{m}$ ). In both directions, significantly higher porosity was observed (Figure 8).

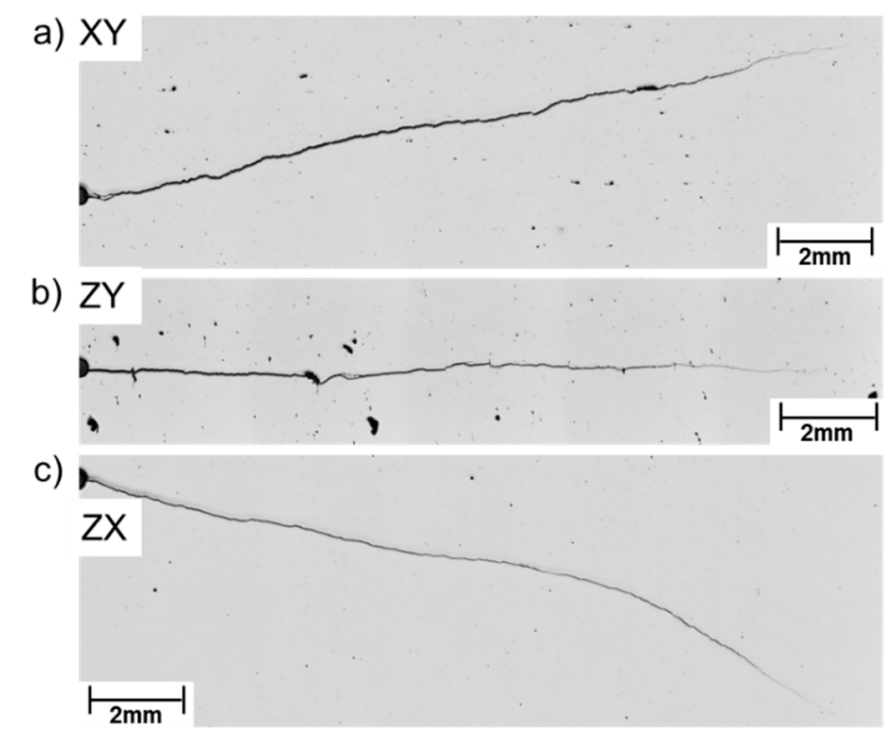

Figure 8. Exemplary distribution of pores with reference to build directions (a) XY, (b) ZY, and (c) ZX.

Pores can act as crack initiators (c.f. Section 3.1). It is therefore hypothesized, that pores were responsible for the lower $\Delta \mathrm{K}$ values for initiation of crack propagation.

Figure 9a displays the CT specimens after fracture. Figure $9 \mathrm{~b}$ depicts the crack paths in the LPBF-manufactured samples. In the $X Y$ direction specimen, the crack propagated perpendicular to the build direction, while in the $\mathrm{ZY}$ orientation, the crack propagated in parallel and in the ZX direction under an angle of $45^{\circ}$ (cf. Figure 10). The lowest da/dN value, accompanied by the highest $\Delta K$ value to initiate crack propagation, was measured at the ZX sample. The best reproducibility was found in the $X Y$ direction specimens (Figure 7). However, only the $Z Y$ direction provided a valid fracture path (according to ASTM regulation [21]). Regardless of build direction, the crack path was transcrystalline (cf. Figures 9b, 10 and 11). Consequently, a weak connection of the individual melt pools can be excluded as a key factor in cracking behavior.

a) Conventional

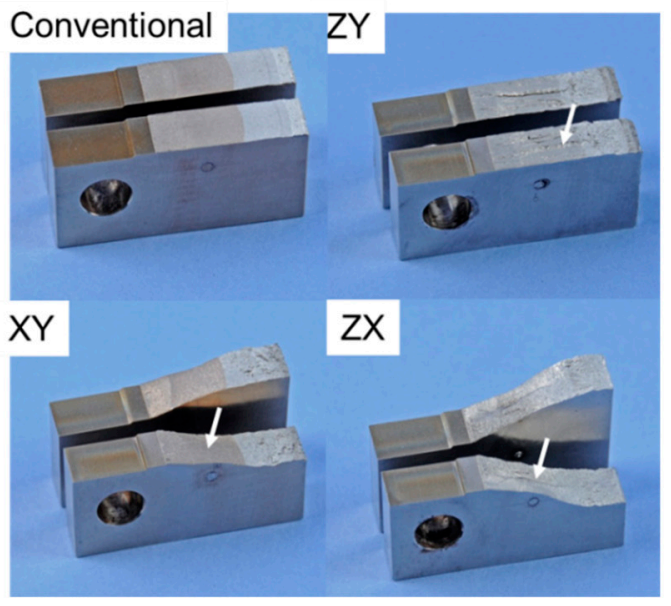

b) ZY

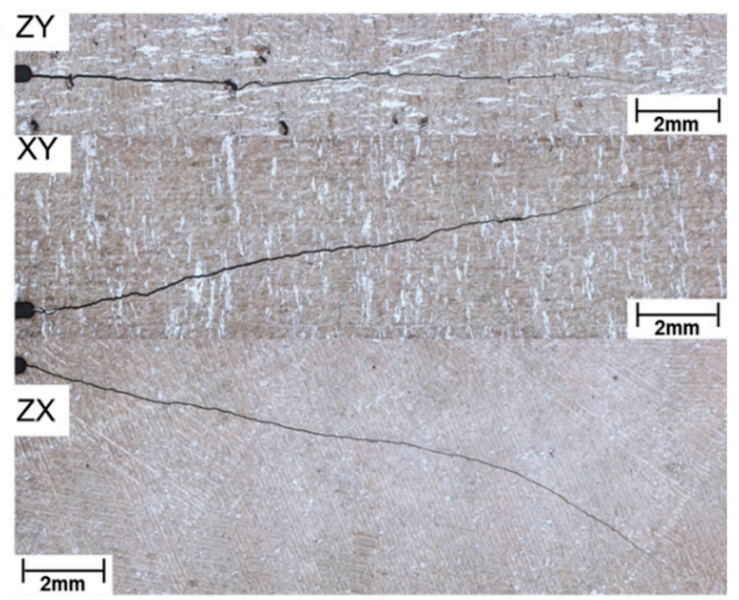

Figure 9. (a) Cracked compact tension (CT) specimens after FCG experiments and (b) longitudinal crack paths (before cracking of the specimens). 

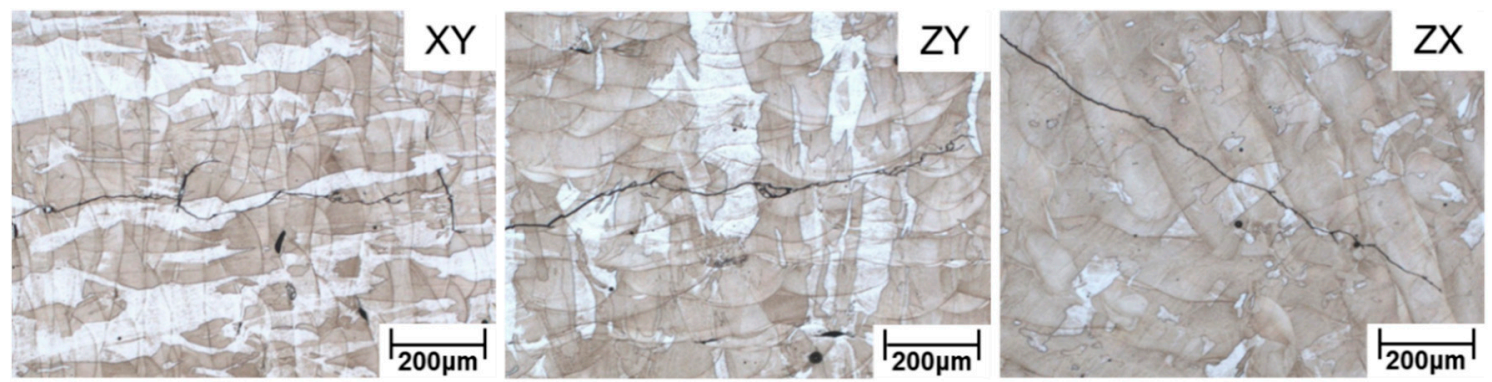

Figure 10. Transcrystalline crack path, regardless of build direction.

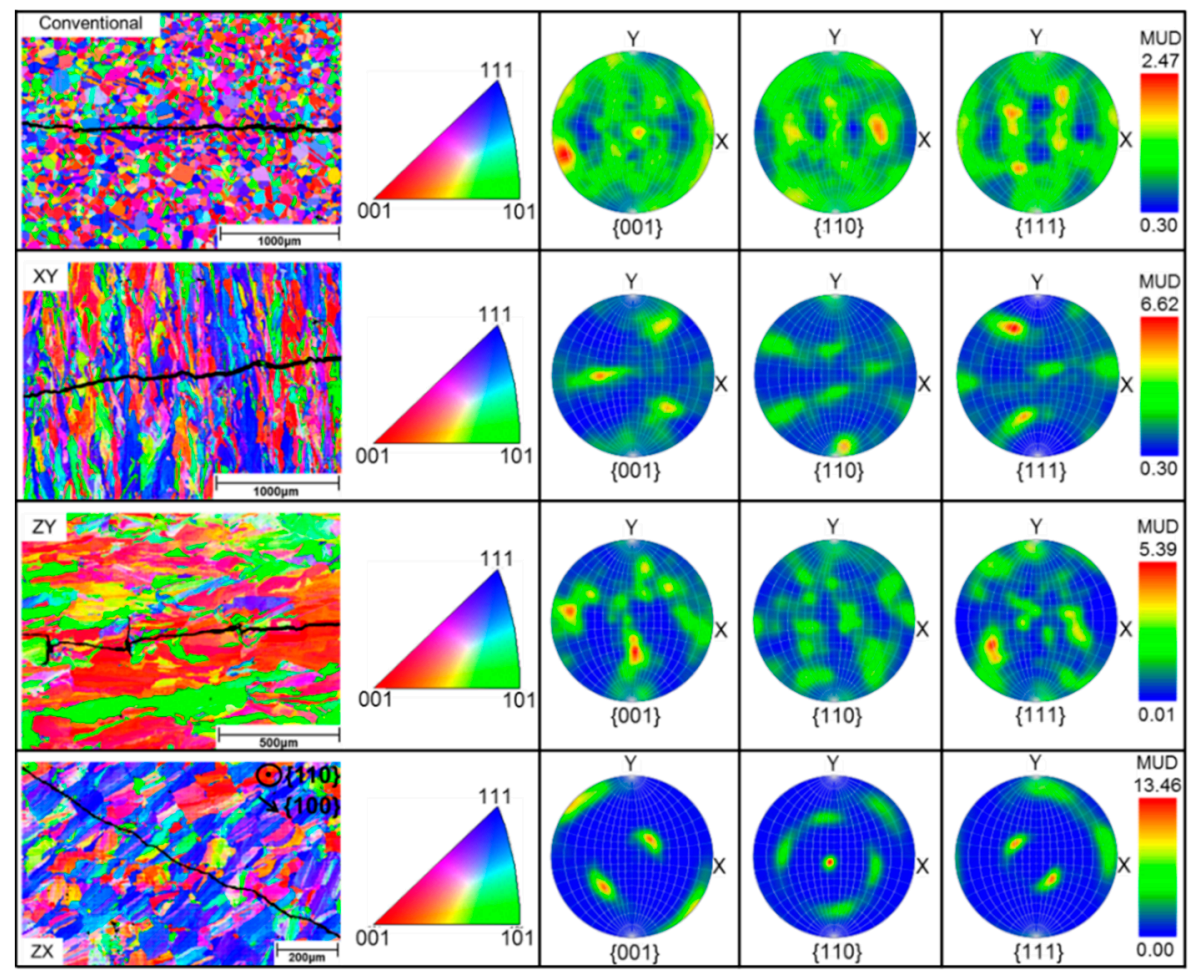

Figure 11. EBSD (electron backscatter diffraction) mappings and corresponding pole figures along fracture paths in conventional and LPBF-manufactured materials (with regard to the three different build directions).

Figure 12 depicts the comparison of the fracture surfaces of conventionally and LPBF-manufactured specimens of different build directions. The fracture surface of conventionally produced material offered features of ductile fracture dimples. In contrast, a mixed fracture mode with ductile and cleavage areas, along with several pores, was found in the additively manufactured $X Y$ and $Z Y$ specimens (Figure 12b,c). The same was observed in the case of the ZX sample, but the crack propagated along lattice planes in the grain interiors (Figure 11d). In this specimen, preferred grain orientations into the $\{001\},\{111\}$, and $\{110\}$ directions were measured. With a percentage of $13.46 \%$, the $\{110\}$ direction was the dominating one (Figure 10). In contrast, the $X Y$ and $Z Y$ specimens exhibited preferred grain orientations into the $\{001\}$ and $\{111\}$ directions. Furthermore, preferential orientation relations in the $X Y$ and ZY were less significant than in the ZX specimen (cf. Figure 11). 

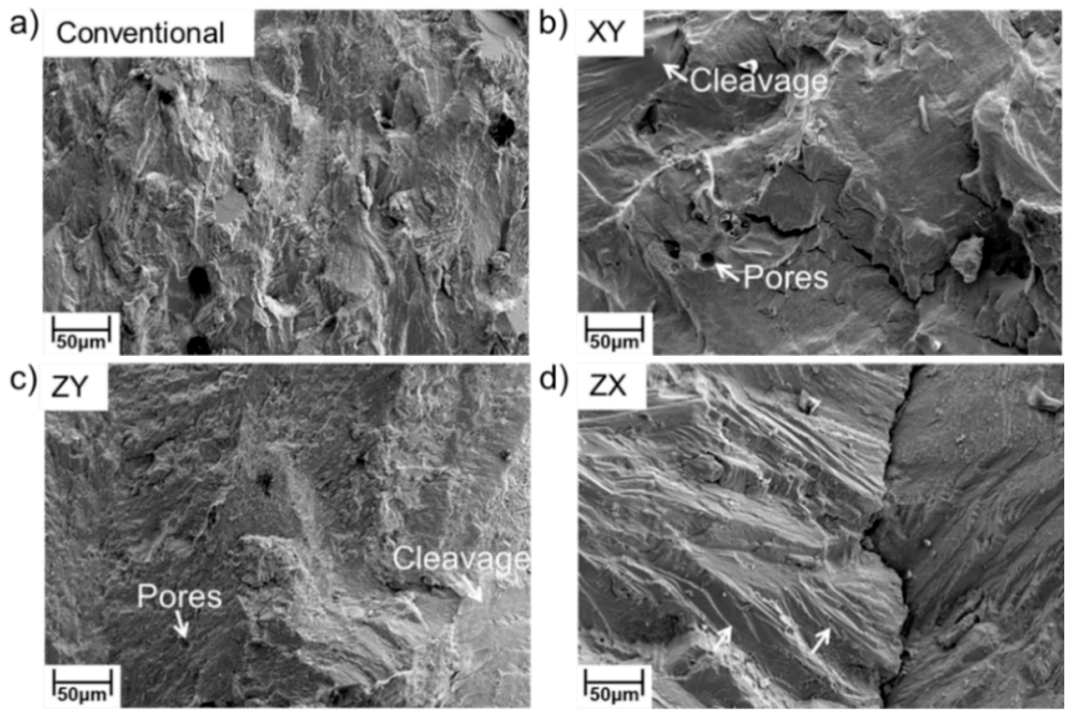

Figure 12. Fracture surfaces of (a) conventional and LPBF-manufactured specimens of build directions (b) XY, (c) ZY, and (d) ZX.

The grains were mainly found to be oriented into the building direction (cf. EBSD mappings in Figure 11). Corresponding to possible/preferred sliding systems in the fcc-lattice, the dislocation movement during cyclic loading took place in the direction of the oblonged grains (cf. local misorientation mappings in Figure 13). In the case of the $X Y$ and ZX specimens, dislocations were oriented perpendicular to the crack path (Figure 13a,c), resulting in an off-horizontal crack path (cf. Figure 9b). In contrast, the main crack propagated horizontally and the dislocations were oriented parallel (Figures $9 \mathrm{~b}$ and $13 \mathrm{~b}$ ) in the $\mathrm{ZY}$ specimen. Crack branching occurred at pores (detailed description included in Section 3.3) due to local stress concentration and changes in stress distribution. Secondary cracks grew partly perpendicular to the longer edges of the pores (Figure 14) before cracks were arrested by dislocations, running parallel to the crack (Figure 13b). Subsequently, the main crack continued to grow horizontally.
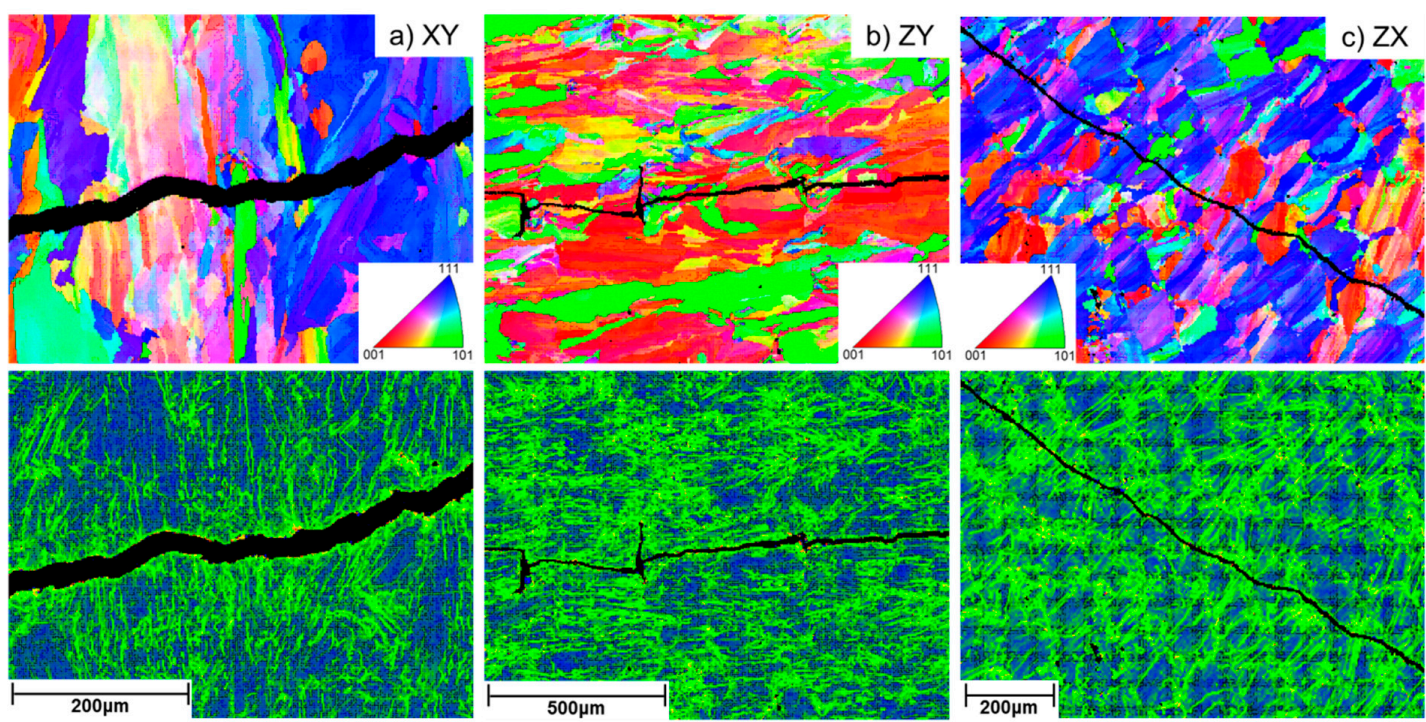

Figure 13. EBSD and local misorientation mappings of additively manufactured specimens referring to the build directions (a) XY, (b) ZY, and (c) ZX. 


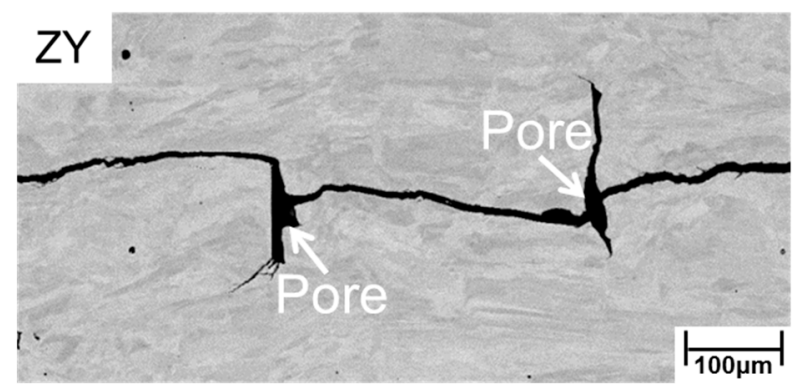

Figure 14. Crack branching at oblonged pores (aspect ratio range of 1.3 to 2.8 ) in the additively manufactured 316L in the ZY specimen.

\subsection{Manufacturing Defects and Their Impact on Fatigue Crack Propagation Behavior}

Parallel to the vessel examinations of Section 3.1, we investigated the fatigue crack growth behavior of conventionally and additively manufactured specimen material. Manufacturing defects were identified and the possible effects on crack propagation behavior were analyzed. The distribution, number density, and morphology of pores depending on build direction were investigated. Thereby, the lowest amount of circular pores (maximum diameter: $80 \mu \mathrm{m}$ ) was observed in the ZX specimen (Figure 8c), which furthermore exhibited the lowest da/dN (Figure 7). In the ZY specimen (Figure 8b), circular and larger, elongated pores (aspect ratio $\approx 1.3-10$ ) were observed, while in the XY (Figure 8a) sample, predominantly small, circular pores (maximum diameter: $60 \mu \mathrm{m}$ ) occurred.

Nevertheless, several larger and elongated pores were found. Both ZY and XY specimens exhibited higher da/dN than the ZX sample (Figure 7). Accordingly, the measured crack length increased considerably faster with increasing number of load cycles (Figure 15).

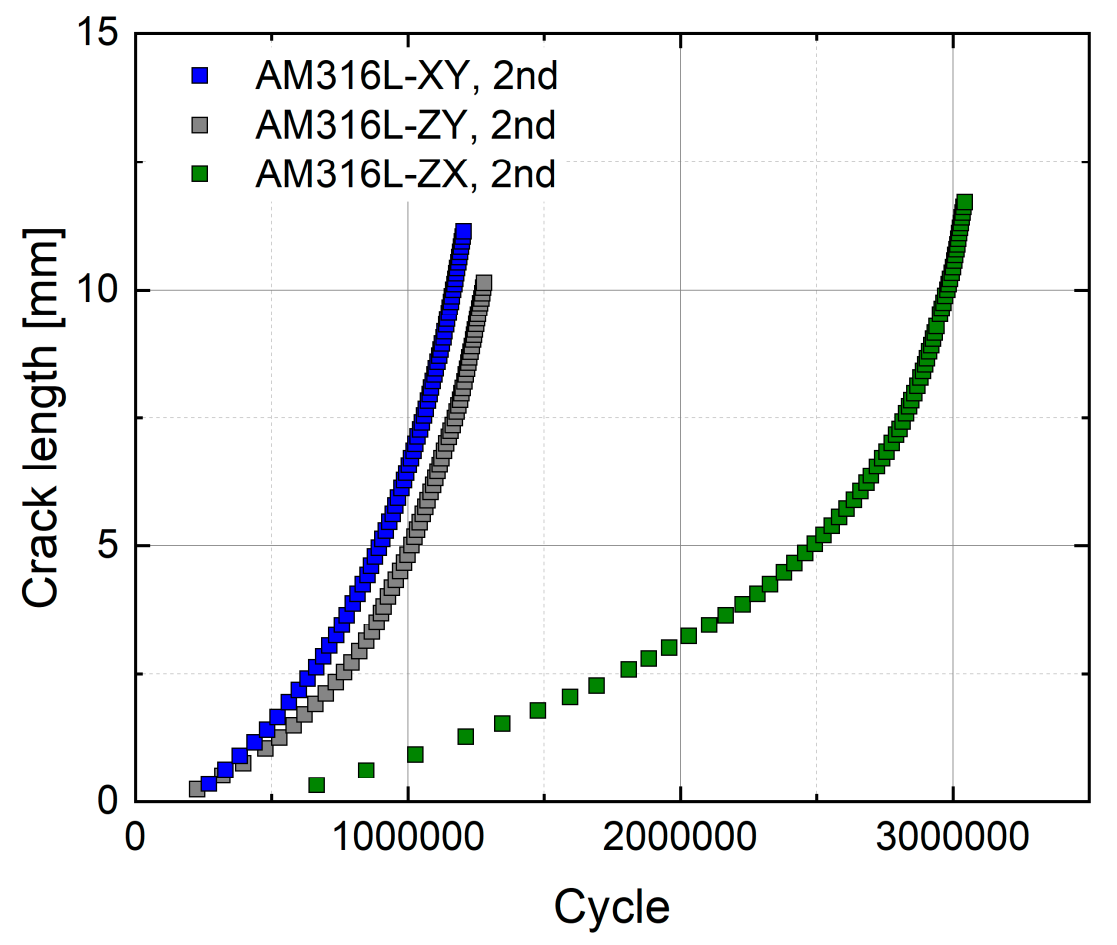

Figure 15. Crack length based on number of loading cycles of additively manufactured material with regard to build direction.

However, because both the curves of the $\mathrm{ZY}$ and $\mathrm{XY}$ specimens increased monotonically, it cannot be concluded that the pores were decisive for the higher crack propagation rate when compared to the 
almost pore-free ZX sample. Furthermore, a tendency of crack branching at pores of an aspect ratio of 1.3-2.8 (Figure 14) was found in the ZY specimen. Material characterization thus confirmed the results of computational analysis of small pores, with a limited effect on crack growth (nevertheless, pores can act as crack initiators) [20].

Crack branching generally leads to a decrease in the crack propagation rate-a further indication that pores may not constitute the decisive factor on differences in crack propagation rates.

Further processing-related issues, such as finely distributed $\mathrm{SiO}_{2}$ particles, may constitute another influencing factor for crack propagation. These were observed in all LPBF-manufactured specimens (Figure 16). On the other hand, such process-related, small, and finely distributed particles may have a strengthening effect, which was not further addressed in this study.
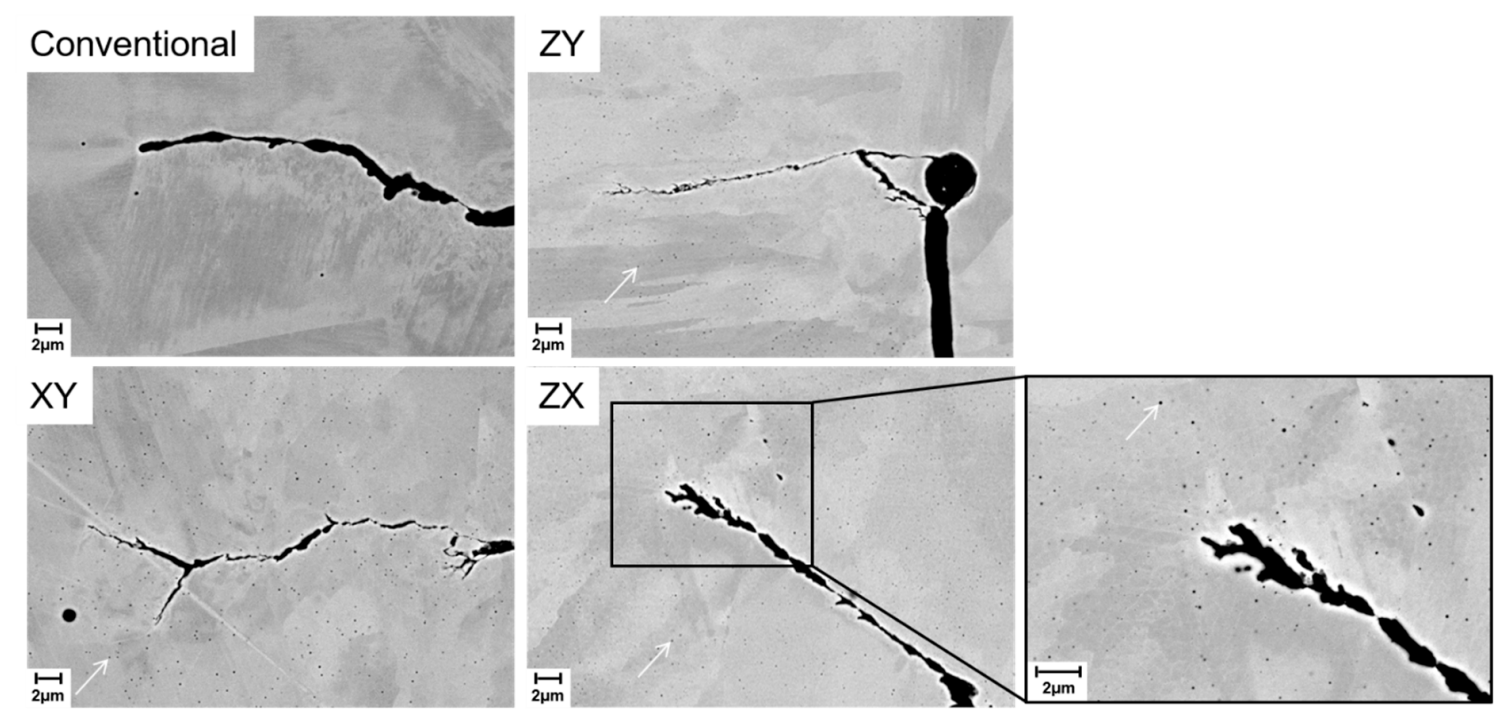

Figure 16. Finely distributed $\mathrm{SiO} 2$ particles in the additively manufactured 316L specimens indicated by white arrows.

Moreover, traces of segregation (Figure 17a) were found. EDX analyses (Figure 17b) in the vicinity of the cracks confirmed enrichment in $\mathrm{Ni}$ and Mo along with depletion in Fe and Mn contents. The concentrations of the alloying elements $\mathrm{Ni}$ and Mo had a direct impact on solid solution hardening (and carbide precipitation) and consequently the strength of the material, which directly influenced resistance to crack growth and therefore crack propagation behavior. A plausible reason for segregation would be excessive cooling rate, resulting in non-equilibrium solidification in the LPBF process. Process optimization towards avoidance of segregation effects could offer further potential for the improvement of crack propagation resistance. 
a)

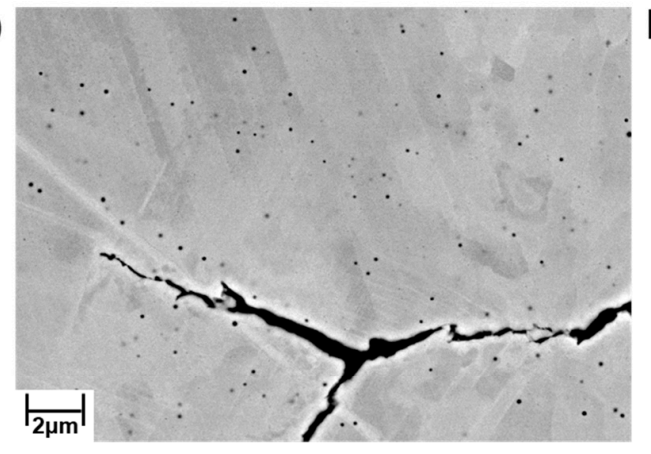

b)

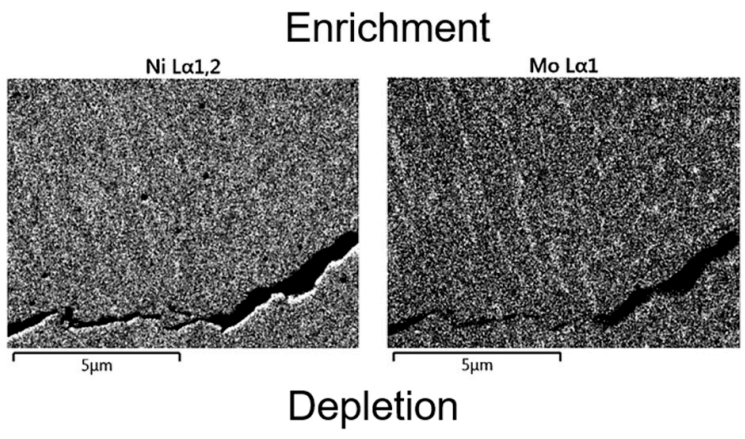

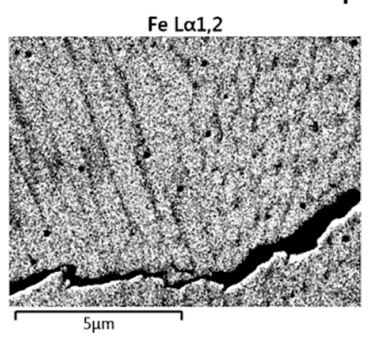

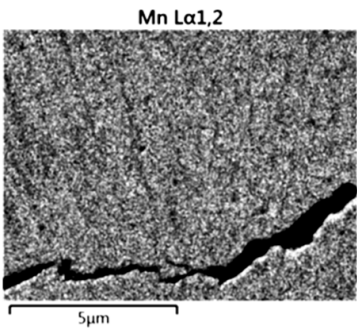

Figure 17. (a) Traces of elemental segregation and (b) corresponding EDX mappings.

\subsection{Novel Materials for Improved Structural Safety}

In Section 3.1 we demonstrated that processing defects, such as pores, may act as notches in critical design regions and thus act as preferred sites of crack initiation. Consequently, if a larger number of pores (i.e., crack starters) in additively manufactured components was present, materials of lower crack propagation rate would be required to at least maintain sufficient component lifetime and safe operation such as that known from conventionally manufactured materials.

Materials tailored for additive manufacturing processes would enable an additional improvement of component lifetime, safety, and cost savings. Of course, safety also depends on the maintenance and management of the structure, but here too, material development can contribute to increasing safety. Application of more robust materials increases the margins of inherently safe operation. The approach is not to minimize pores, but to develop a material with active crack obstruction mechanisms, which inhibit—or at least retard—both crack initiation and crack propagation. Two main mechanisms can be utilized to accomplish this. First is the option of taking advantage of in situ heat treatment by the so-called "temper bead effect" [26-29] during the AM process. The component will then benefit from potential time and cost savings over conventionally produced components. Rapid precipitation kinetics are the essential prerequisite to accomplish this. For this reason, the novel, stainless High Performance Ferritic (HiperFer) steel, developed at Forschungszentrum Juelich GmbH, is a high potential candidate. Strengthening of these steel grades is achieved by a combination of solid solution and intermetallic $(\mathrm{Fe}, \mathrm{Cr}, \mathrm{Si})_{2}(\mathrm{Nb}, \mathrm{W})$ Laves phase particle precipitation [30]. The microstructural and mechanical properties of HiperFer steels are described in detail in [31]. In the current paper, HiperFer-like steel was evaluated on the basis of its in situ heat treatment capability in laser metal deposition (LMD) processing. The second mechanism is to take advantage of "dynamic strengthening" under cyclic loading at high temperatures to actively obstruct crack initiation and propagation and thus enhance component lifetime and safety. In HiperFer, this can achieved by thermomechanically induced precipitation [17] of the Laves phase under cyclic loading, or more generally speaking, under (cyclic) plastic deformation at temperatures above $600{ }^{\circ} \mathrm{C}$ [18]. Figure 18 illustrates a comparison of thermomechanical fatigue curves (100\% out-of-phase TMF experiments, i.e. $\Delta \varepsilon_{\text {mech }} .=-\Delta \varepsilon_{\text {th }}$., meaning that thermal expansion is fully obstructed by the testing machine during cycling through the temperature range of 50 to $650^{\circ} \mathrm{C}$ ) of $316 \mathrm{~L}$, Crofer $22 \mathrm{H}$, and HiperFer $17 \mathrm{Cr} 2$. Crofer $22 \mathrm{H}$ is a predecessor of HiperFer 17Cr2 and was developed at Forschungszentrum Juelich $\mathrm{GmbH}$ for application in high temperature solid oxide fuel cell interconnectors. Crofer22 $\mathrm{H}$ cyclically hardens during the initial 
approximate 30 cycles ( $\approx 1 \%$ of technical lifetime) of fatigue testing by thermomechanically induced precipitation of Laves phase particles, preferentially at dislocations induced by cyclic plasticization. The end of the hardening range corresponds to the maximum of the fatigue curve (cf. " $\mathrm{N}_{\mathrm{h}}$ ", Crofer $22 \mathrm{H}$ curve in Figure 18). The technical lifetime was evaluated from the intersection of linear approximations to the "stable" and the "damage" curve sections of the TMF curves (cf. " $\mathrm{N}_{\mathrm{f}}$ ", Crofer22 $\mathrm{H}$ curve in Figure 18). The beginning of the damage range was evaluated by deviation of the fatigue curve from a linear approximation to the stable curve section (cf. " $\mathrm{N}_{\mathrm{d}}$ ", Crofer22 $\mathrm{H}$ curve in Figure 18). During the initial 30 cycles, Crofer $22 \mathrm{H}$ hardened by $205 \mathrm{MPa}$, which is equivalent to an increase in strength of $38 \%$ (Table 6). After reaching the maximum stress range, Crofer $22 \mathrm{H}$ was characterized by a comparatively steep drop in stress range before it entered the stable range (Figure 18) at around 380 cycles. The HiperFer $17 \mathrm{Cr} 2$ steel in contrast continuously hardened within the initial 70 cycles $\approx \approx \%$ of technical lifetime), avoiding the steep drop in stress range and directly entering the stable range on a higher stress range level (Figure 18). The hardening range increased to $236 \mathrm{MPa}$, corresponding to an increase in strength of $42 \%$ (Table 6 ). These differences in behavior were caused by differing precipitation kinetics and phase fractions of Laves phase precipitates. Dislocations induced by cyclic plasticization cause (temporary) hardening. Crofer22 $\mathrm{H}$ and HiperFer dislocations were immediately decorated and pinned by nucleating Laves phase particles, i.e., the temporary strengthening effect became quasi-permanent. The chemical composition of HiperFer $17 \mathrm{Cr} 2$ is optimized for high volume fraction of the Laves phase. For this reason, the precipitation process lasts longer $\left(5 \% / 1 \%\right.$ of technical lifetime HiperFer/Crofer ${ }^{\circledR} 22$ $\mathrm{H}$ ) and creates more dislocation pinning particles in HiperFer, which causes increased strengthening and thus stabilization of the stress range on a higher level. In Crofer $22 \mathrm{H}$, less dislocations were pinned by precipitates, i.e., a smaller extent of temporary dislocation strengthening became quasi-permanent, which caused a decrease in stress range after the maximum was reached.

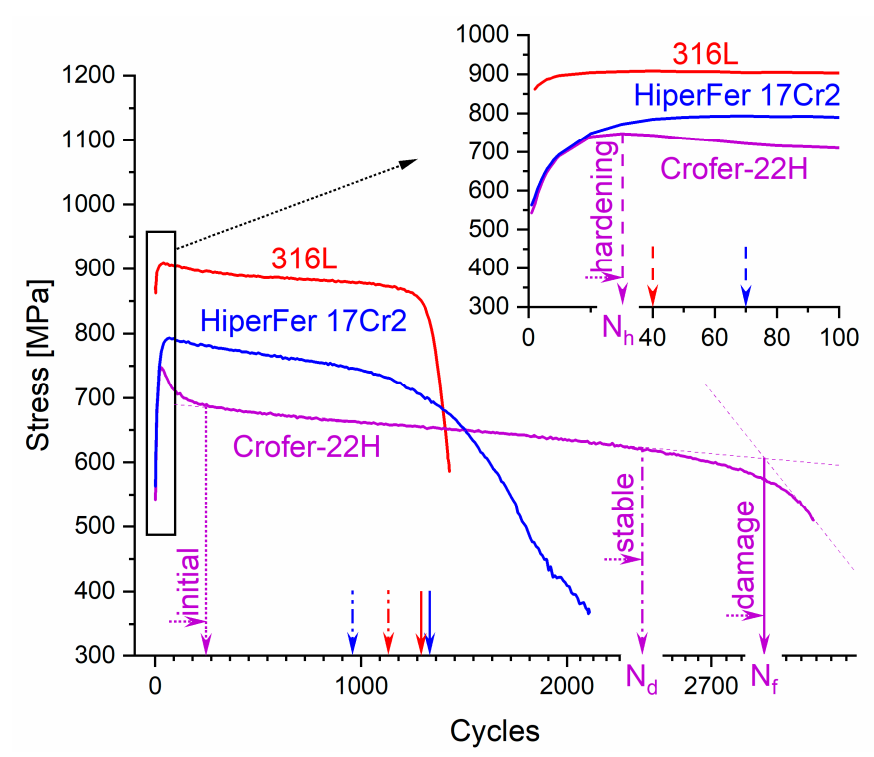

Figure 18. Comparison of thermomechanical fatigue curves of 316L [18], Crofer22 $\mathrm{H}$, and HiperFer $17 \mathrm{Cr} 2\left(100 \%\right.$ out-of-phase cycles (i.e. $\left.\varepsilon_{\text {mech }}=-\varepsilon_{\text {th }} \cdot\right), \Delta \mathrm{T}=50-650{ }^{\circ} \mathrm{C}, \mathrm{dT} / \mathrm{dt}=10 \mathrm{Ks}^{-1}, \mathrm{t}_{\mathrm{h}}=0$ at $\mathrm{T}_{\min }$ and $\left.\mathrm{T}_{\max }\right)[18]$. 
Table 6. Strengthening during thermomechanical fatigue (TMF) loading $\left(\sigma_{h}\right)$, hardening cycles $\left(\mathrm{N}_{h}\right)$, damage initiation $\left(\mathrm{N}_{\mathrm{d}}\right)$, technical TMF lifetime $\left(\mathrm{N}_{\mathrm{f}}\right)$, and damage ranges (i.e., relation of $\mathrm{N}_{\mathrm{f}}$ and $\mathrm{N}_{\mathrm{d}}$; experimental parameters: $50-650{ }^{\circ} \mathrm{C}, \varepsilon_{\text {mech }}=-\varepsilon_{\text {th }}, \mathrm{dT} / \mathrm{dt}=10 \mathrm{Ks}^{-1}, \mathrm{t}_{\mathrm{h}}=0$ at $\mathrm{T}_{\min }$ and $\left.\mathrm{T}_{\max }\right)$.

\begin{tabular}{cccccc}
\hline Material & $\boldsymbol{\sigma}_{\mathbf{h}}$ & $\mathbf{N}_{\mathbf{h}}$ & $\mathbf{N}_{\mathbf{d}}$ & $\mathbf{N}_{\mathbf{f}}$ & Damage Range \\
\hline Crofer22 H & $\approx 205 \mathrm{MPa}(38 \%)$ & 30 & 2400 & 2930 & $18.1 \%$ \\
HiperFer 17Cr2 & $\approx 236 \mathrm{MPa}(42 \%)$ & 70 & 974 & 1389 & $29.9 \%$ \\
316L & $\approx 47 \mathrm{MPa}(5.4 \%)$ & 40 & 1143 & 1326 & $13.8 \%$ \\
\hline
\end{tabular}

Because the stable stress range was lower, damage occurred later in Crofer22 H. Despite the high level of strain, obstruction in the experiments the S-N curves of Crofer22 $\mathrm{H}$ and HiperFer decreased moderately, especially in comparison to 316L. The austenitic steel strengthened in the hardening range by only $47 \mathrm{MPa}$, which corresponded to an increase in strength of only $5.4 \%$ (Table 6). 316L failed abruptly, with only a $\approx 13.8 \%$ damage range. With $29.9 \%$ of the lifetime in the damage range, HiperFer was found to be the superior material. Despite the fact that the effective strain range in the austenitic 316L steel $\left(\Delta \varepsilon_{\text {th }}\right.$, i.e. $\Delta \varepsilon_{\text {mech }} \cdot$ HiperFer $=0.71 \%$, while $\left.\Delta \varepsilon_{\text {mech }} 316 \mathrm{~L}=1.14 \%\right)$, i.e., dislocation hardening, was much higher, HiperFer reached a comparably high stable stress range level.

The TMF experiments demonstrated the high fatigue resistance potential of HiperFer steel. However, the total lifetime of a component is composed of the sum of the technical lifetime up to the initiation of detectable cracks (characterized for example by TMF life) and the residual lifetime (characterized by FCG). For this reason, it is necessary to develop a material that actively obstructs both the initiation and propagation of cracks in order to exploit the maximum material and component lifetime. HiperFer steels were developed with this objective in mind [18]. A comparison of the ambient temperature FCG data (where thermomechanically induced precipitation in Laves phase-strengthened ferritic steel is not yet effective) of AM316L, conventionally produced 316L, and Crofer22 $\mathrm{H}$ in the precipitation annealed state gave an impression of the potential for the obstruction of fatigue cracks, inherent in these steel grades (Figure 19).

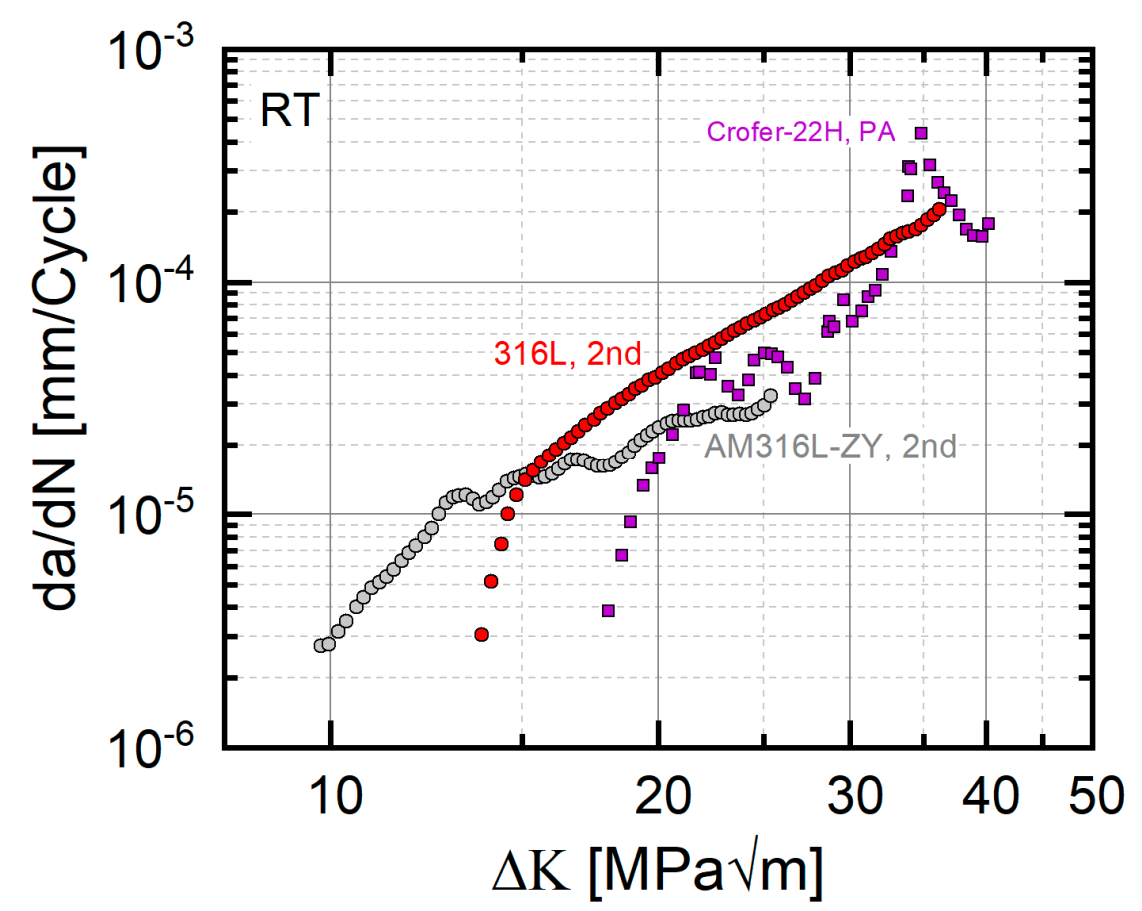

Figure 19. Cyclic crack propagation curves of additively manufactured 316L (AM316L-ZY), conventionally manufactured 316L, and Crofer $22 \mathrm{H}$ (after precipitation annealing: 0.5 to $10 \mathrm{~h}$ from $600-650{ }^{\circ} \mathrm{C}$ ) at ambient temperature. 
In comparison to additively/conventionally manufactured austenitic 316L (cf. curves "AM316L-ZY, $2^{\text {nd" }} /$ " $316 \mathrm{~L}, 2^{\text {nd" }}$ in Figure 19), it takes almost twice/1.5 times the stress intensity to initiate crack propagation in conventionally processed Crofer $22 \mathrm{H}$. Over the whole stress intensity range, the crack propagation rate was lower than in conventional 316L. Crack propagation in the second, additively manufactured 316L specimen (AM316L-ZY) was slightly lower in comparison to Crofer22 $\mathrm{H}$, but the specimen already hit the test termination criterion $(\mathrm{a} / \mathrm{W}=0.7)$ when Crofer $22 \mathrm{H}$ just reached the stable region of the cyclic crack propagation curve. However, HiperFer-like steel can only exploit its maximum potential at temperatures around $600{ }^{\circ} \mathrm{C}$ or above. As outlined in the previous section (cyclic), plastic deformation in fatigue loading in this temperature range results in "reactive precipitation hardening" [32], which not only leads to higher strength, but to active crack obstruction [17]. On the basis of this intrinsic mechanism, HiperFer 17Cr2 (conventionally manufactured variant) can reach up to an order of magnitude of higher residual fatigue lifetime than austenitic 316L (Figure 20).

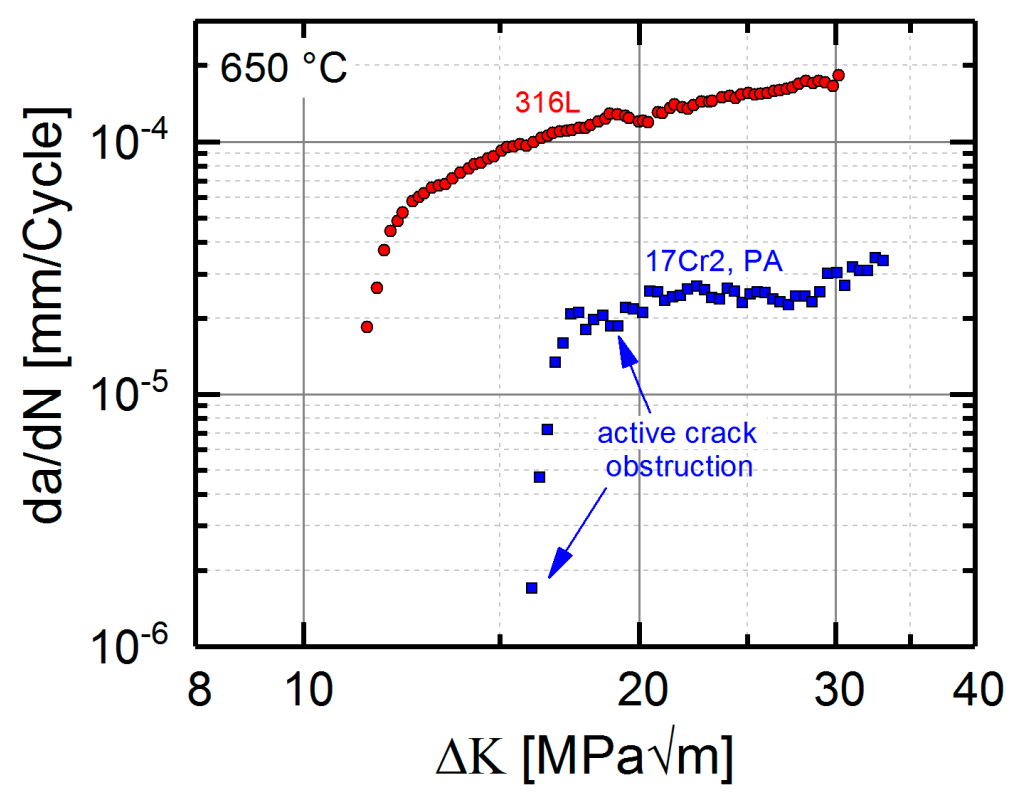

Figure 20. FCG data of 316L and HiperFer 17Cr2 (after precipitation annealing: 0.5 to $10 \mathrm{~h}$ from $\left.600-650{ }^{\circ} \mathrm{C}\right)$ at $650{ }^{\circ} \mathrm{C}[18]$.

Crack propagation in HiperFer $17 \mathrm{Cr} 2$ remained at an almost constant velocity over a comparatively wide range of the cyclic crack propagation curve, despite increasing stress intensity $\Delta \mathrm{K}$.

In order to investigate the potential of the alloying system for AM, we developed a first model alloy (HiperFer ${ }^{A M}$ (Additive Manufacturing) for the additive manufacturing processes. The alloy composition was $22 \mathrm{Cr}, 2 \mathrm{~W}, 1.5 \mathrm{Nb}$, and $1 \mathrm{Si}$ (wt.-\%). The increased $\mathrm{Nb}$ and Si contents in comparison to HiperFer $17 \mathrm{Cr} 2$ in combination with higher cooling rates in the AM process resulted in a highly supersaturated solid solution in the as-processed state, which in turn led to rapid precipitation kinetics, caused by high precipitation pressure in the direction of equilibrium. This resulted in a large amount of fine Laves phase particles (Figure 21), even after the comparatively short high temperature periods of in situ heat treatment. Figure 22 displays a typical microstructure of LMD-processed (by Fraunhofer ILT, Aachen) HiperFer ${ }^{\mathrm{AM}}$ powder.

In addition, the grain boundaries were occupied by Laves phase particles (Figure 21) in the as-manufactured state, stabilizing the grain structure without embrittling the material. As outlined in [16,17], this is an important issue to enable profit from dynamic strengthening. Pores contained in additively manufactured materials (cf. Figure 21) acted as notches and led to accumulation of plastic strain in the surrounding material during cyclic loading. In HiperFer ${ }^{\mathrm{AM}}$, this led to thermomechanically induced precipitation [18,32] of Laves phase particles at these dislocations 
and strengthened the surroundings of the pores and actively delayed crack initiation. Further microstructural characteristics of HiperFer were particle-covered high angle grain boundaries and the particle-free zones (PFZs [31,33-35]) that formed along these (Figure 21). Especially in higher tungsten-alloyed HiperFer, crack propagation through the densely particle populated grain interiors or to overcome the particle-covered grain boundaries is quite energy consuming.

For this reason, cracks did not necessarily follow fatigue typical intragranular paths, but to some extent followed the PFZs (Figure 23). In consequence, crack growth could potentially be controlled by intelligent adjustment of PFZ width and grain size (i.e., particle-free volume).

A preliminary investigation into this issue covered a beam diameter variation in the LMD process (by Fraunhofer ILT, Aachen) from 3 to $0.66 \mathrm{~mm}$ and successfully provided differing microstructures. Three millimeters of beam diameter resulted in predominantly large, oriented, rod-shaped grains (Figure 24a), while the $0.66 \mathrm{~mm}$ diameter tended to produce smaller, less rod-shaped, partly almost globular grains (Figure 24b). Obviously grain size can be adjusted by changing the AM process parameters. By this, even microstructural adjustment to specific applications seems feasible. For example, the HiperFer ${ }^{\mathrm{AM}}$ microstructure presented in Figure 24a is suitable for application in the creep regime, while the microstructure displayed in Figure $24 \mathrm{~b}$ could be suitable for higher strength applications at low temperatures. Of course, mutual optimization of the chemical composition of HiperFer $^{\mathrm{AM}}$ to specific additive manufacturing techniques (LMD, LPBF, EBM (electron beam melting), WAAM (wire and arc additive manufacturing)) and vice versa is yet to come.

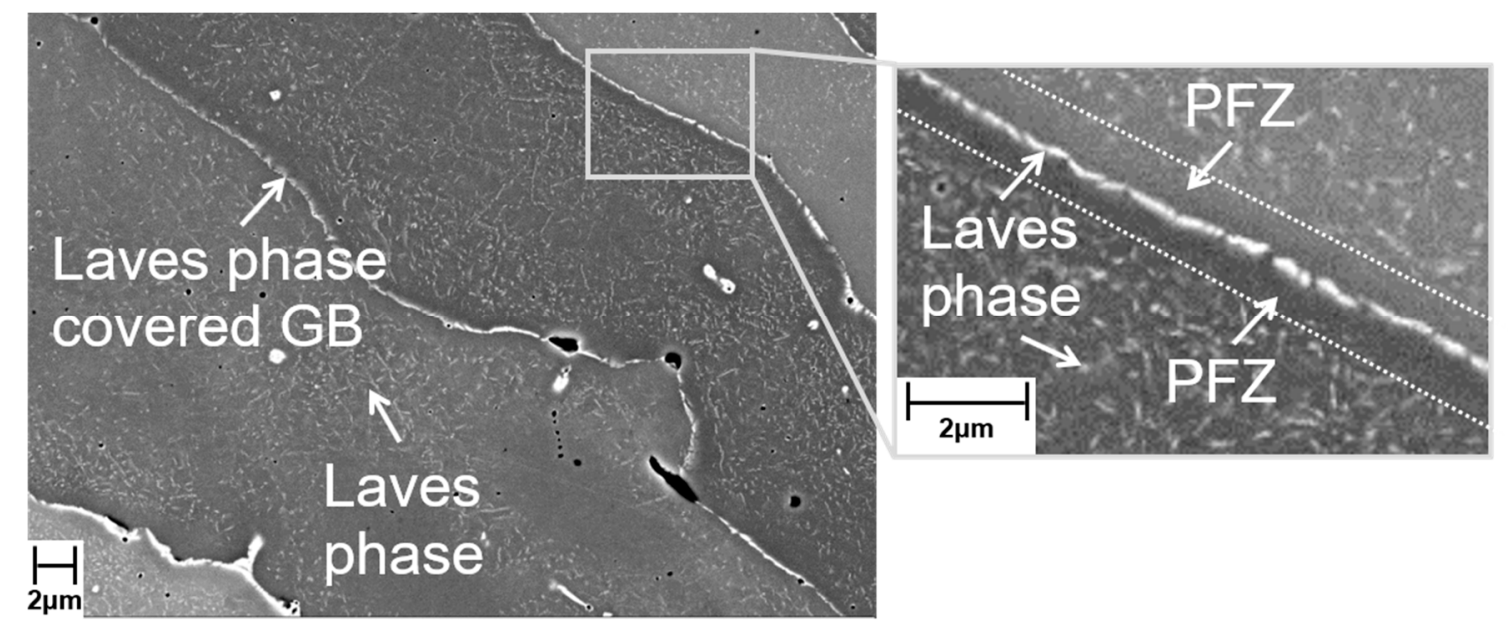

Figure 21. Microstructure characteristics of LMD-manufactured HiperFer ${ }^{\mathrm{AM}}$ (process parameters given in Table 4).

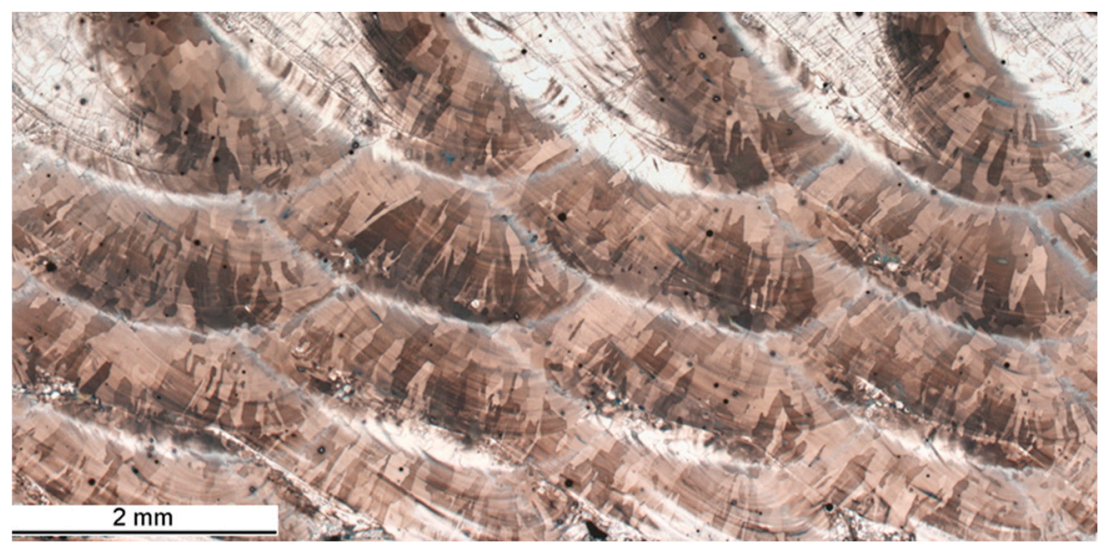

Figure 22. Microstructure overview of LMD-processed HiperFer ${ }^{\mathrm{AM}}$ (3 $\mathrm{mm}$ beam diameter). 


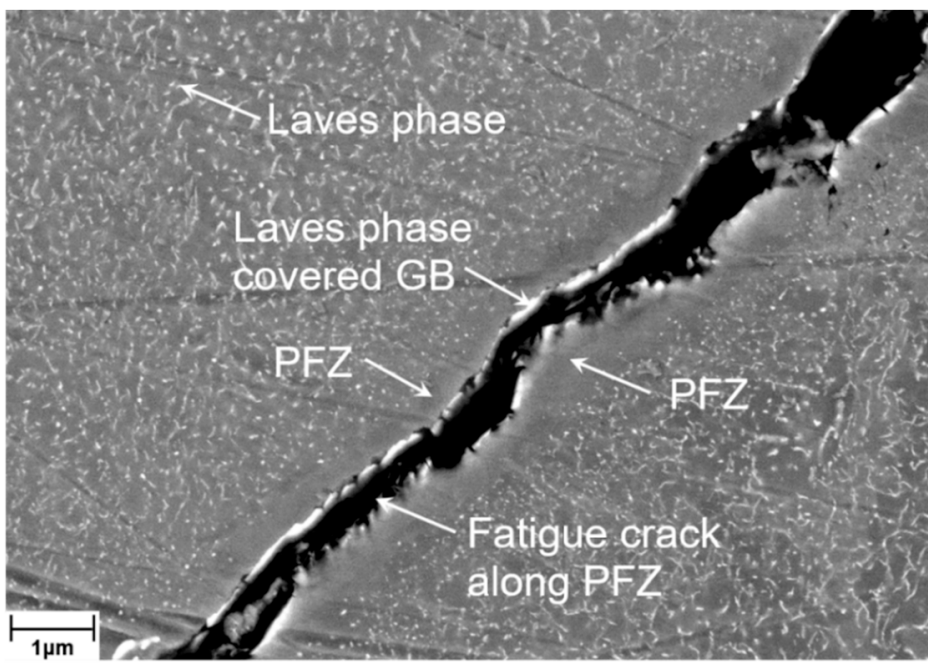

Figure 23. Fatigue cracking within particle-free zones (PFZs) in conventionally produced and higher tungsten-alloyed HiperFer.

a)

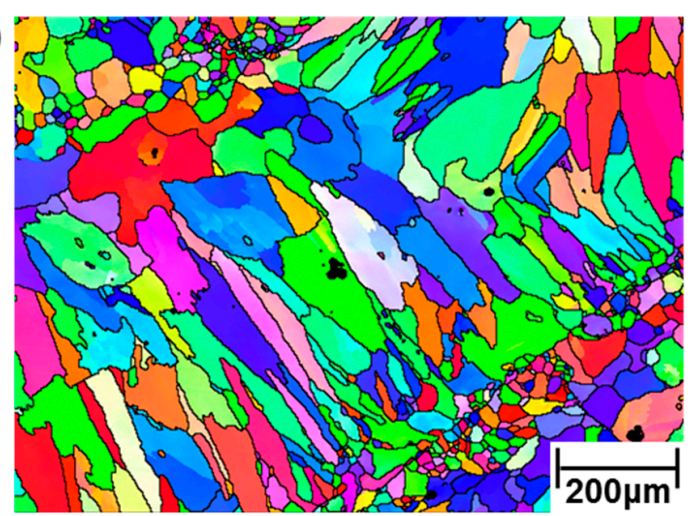

b)

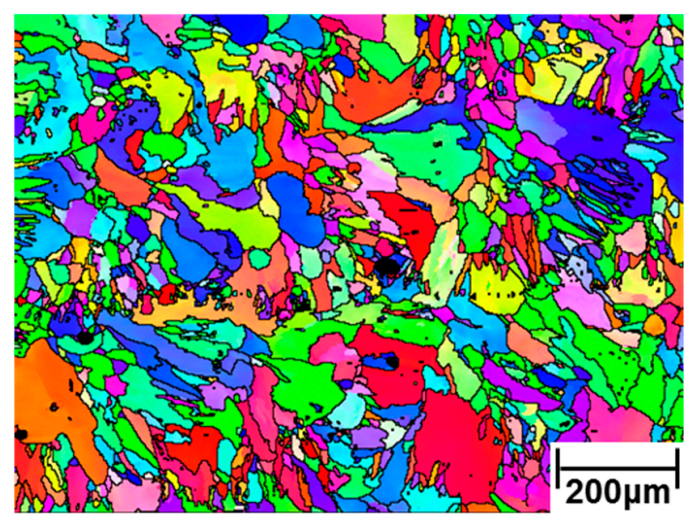

Figure 24. EBSD micrographs (IPFs) of LMD-processed HiperFer ${ }^{A M}$ : (a) $3 \mathrm{~mm}$ of beam diameter, showing rod-shaped grains (in the center region), adjacent to equi-axed grains and fine grain formation in re-molten regions; (b) $0.66 \mathrm{~mm}$ beam diameter, depicting less and thinner rod-shaped grains in the center and generally smaller grain size.

\section{Conclusions}

\subsection{Influence of Crack Propagation Rate on Component Lifetime}

According to the fracture-mechanics based damage tolerance concept, crack propagation rate is a crucial factor, controlling the residual lifetime of components and the estimation of in-service inspection intervals. To exemplarily illustrate this, we calculated the effect of the measured crack propagation rates on the growth of a postulated initial crack in the experimental vessel (outlined in Section 2.1, cf. Figures 1 and 25). The stress calculation was carried out by applying the finite element analysis (FEA) software package ANSYS 19.2. The calculated von Mises equivalent stress in the stress concentration area around the nozzle intersection of the pressure vessel under an internal pressure of 133.1 bar (permissible pressure according to technical code [36]) is given in Figure 26. 


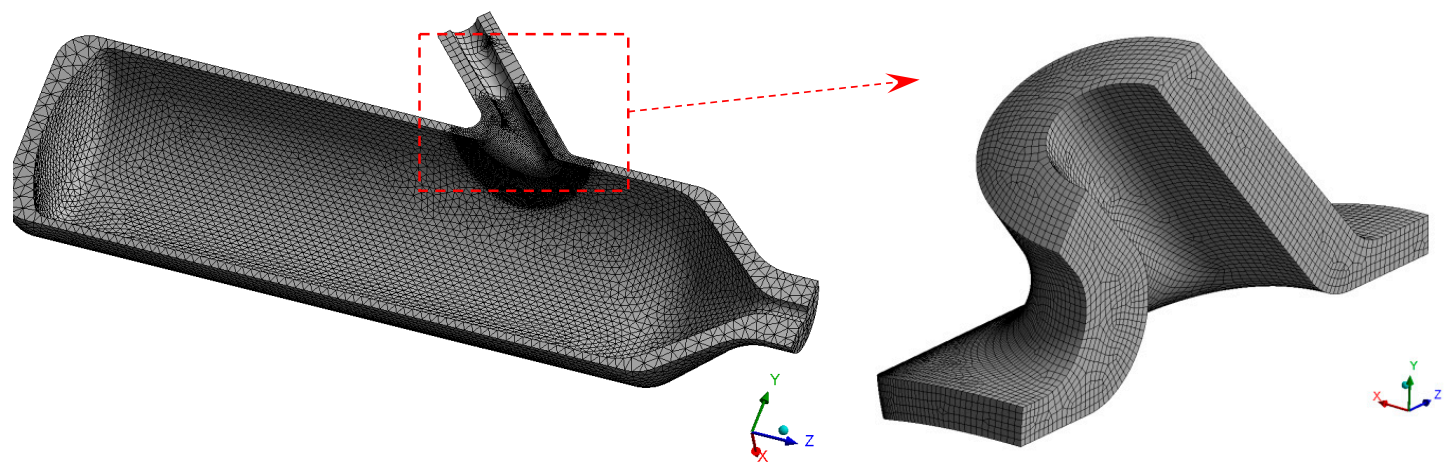

Figure 25. Finite element model of the pressure vessel with nozzle intersection geometry.

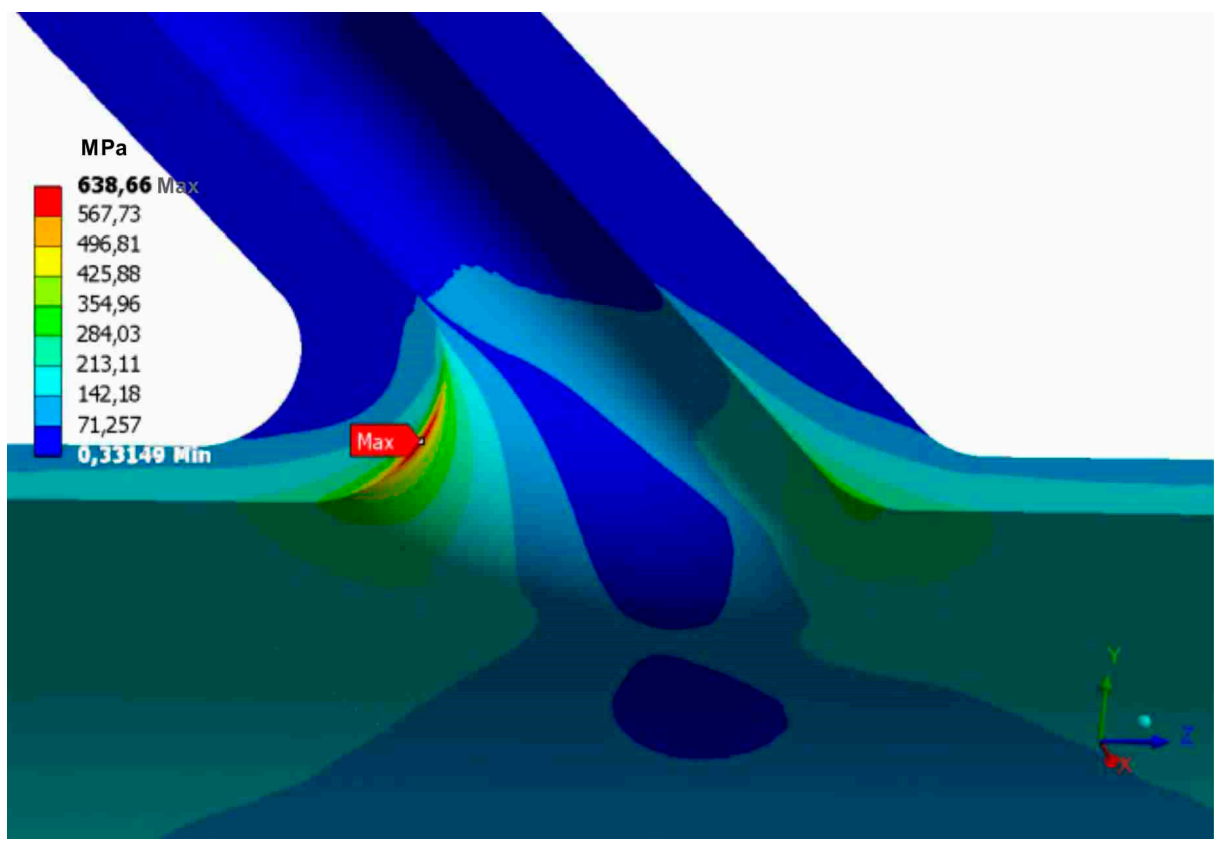

Figure 26. Stress distribution (von Mises) in the nozzle intersection area at 133.1 bar internal pressure.

For the analytical crack growth calculations, we postulated a semi-elliptical surface-crack, parallel to the vessel axis in the maximum stress zone at the nozzle intersection (cf. red area in Figure 1). The stress intensity factor solution for the two-dimensional stress fields (according to Varfolomeyev et al. [37]) was utilized for the calculation, applying the fracture mechanics software tool IWM VERB [38]. The postulated initial crack had a depth of $2 \mathrm{~mm}$ and a semi-axial aspect ratio of 1/10. Cyclic loading was accomplished by alternating the internal pressure between zero and 133.1 bar. To simulate and show any relevant and distinguishable fatigue crack growth and to exceed all threshold values for FCG, we used a scaling factor of 2 on the stresses of Figure 1.

All the measured crack propagation curves were approximated by enveloping a linear relationship in double logarithmic plotting according to the Paris' Law [39] and compared to the standard crack propagation rates for ferritic and austenitic steels contained in the ASME Boiler and Pressure Vessel Code [40].

Figures 27 and 28 display the impact of the measured crack propagation rates in calculated crack growth diagrams at ambient and elevated temperatures, respectively. In both diagrams, the standard crack propagation rates for ferritic and austenitic steels (in air) according to the ASME Boiler and Pressure Vessel Code [40] are included for comparison to the crack propagation rates measured at 316L, 
Crofer22 $\mathrm{H}$, and HiperFer. The results exemplarily show the enormous influence of material inherent resistance to crack growth on fatigue exhaustion and residual lifetime of components.

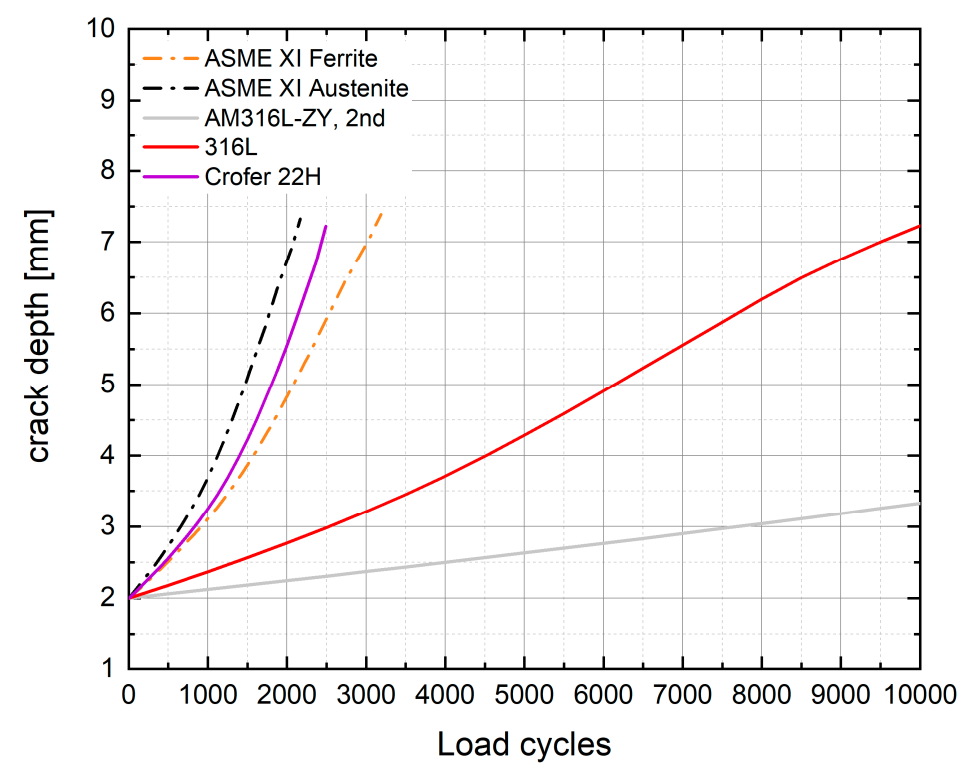

Figure 27. Calculated growth of a postulated $2 \mathrm{~mm}$ deep and $40 \mathrm{~mm}$ wide surface crack under cyclic loading ( $\mathrm{f}=20 \mathrm{~Hz}, \mathrm{R}=0.1$ ) in various materials (ASME curves for comparison) at ambient temperature.

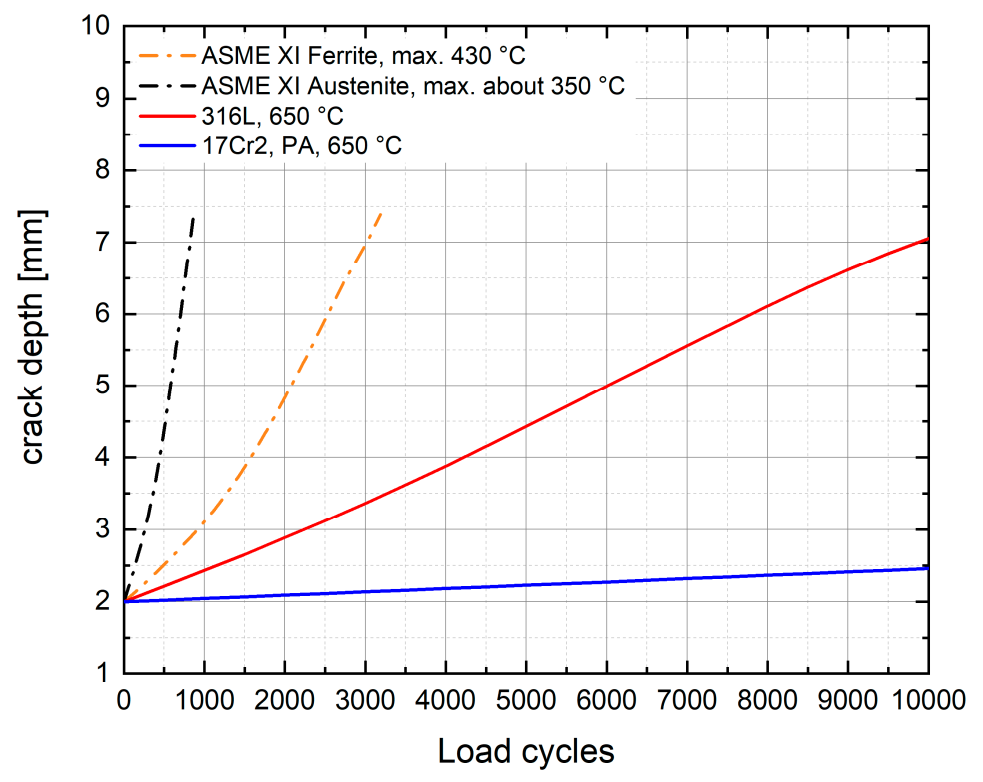

Figure 28. Calculated growth of a postulated $2 \mathrm{~mm}$ deep and $40 \mathrm{~mm}$ wide surface crack under cyclic loading $\left(\mathrm{f}=20 \mathrm{~Hz}, \mathrm{R}=0.1, \mathrm{~T}=650^{\circ} \mathrm{C}\right.$ ) in various materials (ASME curves for comparison) at elevated temperatures.

\subsection{Summary and Outlook}

Additively manufactured materials and components usually have manufacturing defects. For this reason, development aims to reduce the number of defects, pores in particular, in components by optimizing the process parameters and to improve pore detection, especially in critical design areas. Moreover, it is necessary to develop or to adapt existing standards for safe application of additively manufactured components. Approval procedures are still hampered by the problems of standardizing the manufacturing process. The results of this study demonstrate that these challenges can be solved 
by different approaches. Pores can act as notches in critical design areas and therefore lead to crack initiation, but crack growth is subsequently retarded because the crack must be re-initiated [20]. In sum, this can lead to slower crack growth. Hence, it is recommended to include the fracture mechanics-based damage tolerance concept already in the design and manufacturing phase for strength and durability assessment. Porosity and fracture mechanics-based damage tolerance analysis-two aspects usually considered separately-should be interlinked. The key factor for residual lifetime and in-service inspection interval estimation within a fracture mechanics-based damage tolerance concept is viable crack propagation data. For this purpose, state of the art additively manufactured 316L material was investigated. From commercially available powder, AM-processed 316L provides increased cracking resistance in comparison to conventionally produced material. However, in additively manufactured material, crack propagation is initiated at lower stress intensity than in conventionally produced material. This can be attributed to the fact that small pores in particular can favor the initiation of crack propagation. Grain orientation, depending on build direction and the resulting preferred slip systems, were identified as being responsible for non-horizontal or horizontal cracking. Weak connection of the individual melt pools was eliminated as a possible cause because all the cracks propagated transcrystalline, regardless of build direction.

Processing defects such as pores, finely distributed $\mathrm{SiO}_{2}$ particles, and segregation of alloying elements were identified. Different pore distributions, geometries, and sizes were observed on the basis of on build direction. A tendency to crack branching at pores of aspect ratios ranging from 1.3 to 2.8 was observed in the ZY specimen. Evaluation of the experimental results did not indicate a significant impact of small pores on crack propagation behavior. This was congruent to computational analyses [20].

The very small and finely dispersed $\mathrm{SiO}_{2}$ particles, observed in all the additively manufactured 316L specimens, did not unfold recognizable, negative effects.

Segregation of alloying elements may have an indirect impact on crack propagation behavior. Areas, enriched in Ni and Mo, as well as others, depleted in Fe and Mn, were identified. Ni and Mo influenced solid solution hardening and thus the local strength of the material. Strength, in turn, had a direct impact on resistance to crack growth and consequently on crack propagation behavior. High cooling rates, leading to non-equilibrium solidification, were thought to be responsible for the segregation phenomena.

316L, additively manufactured, utilizing process parameters according to the current state of technology, demonstrated significantly improved crack propagation behavior over conventionally produced material. Nonetheless, this study showed a variety of approaches for further improvement. The issue of process-related pores, which can act as crack initiators, remains. In the vast majority of cases, previous approaches employed established, commercial materials. Materials, specifically developed for additive manufacturing in combination with mutual process optimization, do still play a minor role. In the present study, a tailor-made material was developed especially for additive manufacturing, which on the one hand draws advantage from the manufacturing process itself and on the other hand compensates for process-related disadvantages. A first HiperFer ${ }^{\mathrm{AM}}$ model alloy was successfully manufactured from a mixture of individual powders (pre-alloyed powder thus will provide further potential for improvement) utilizing the LMD process. Material-related advantages include optimized precipitation kinetics, enabling in situ heat treatment capability and the adjustment of the microstructure to the respective application. Process-related disadvantages such as pores, which can act as crack initiators, can be compensated to a certain level by material inherent, active crack obstruction mechanisms. The material reacts by thermomechanically induced precipitation of Laves phase particles to (cyclic) plastic deformation at temperatures about $600{ }^{\circ} \mathrm{C}$ and higher. As a result, not only the technical TMF lifetime, but also the residual lifetime and thus the total lifetime of a component can greatly be increased. These benefits have been demonstrated on HiperFer alloys, developed for the conventional production route and not yet specifically optimized for additive manufacturing. The presented HiperFer ${ }^{\mathrm{AM}}$ shall serve as a basis for further alloy development, especially for additive 
manufacturing purposes. The next practical steps are further development of alloy composition and production of pre-alloyed powders for the LPBF process. Powder manufacturing for HiperFer ${ }^{\mathrm{AM}}$ is currently in progress and future work will include processing, general material, and component testing (such as that described for 316L in the present study).

Author Contributions: Conceptualization, T.F.; methodology, T.F. and B.K.; software, D.R., A.S., R.T., and T.F., validation, T.F., B.K., D.R., A.S., R.T., and M.B.W., formal analysis, T.F., B.K., D.R., A.S., R.T., and M.B.W.; LMD manufacturing, M.B.W.; investigation, T.F., B.K., D.R., A.S., R.T., and M.B.W.; resources, A.S. and B.K.; data curation, T.F., D.R., A.S., and R.T.; writing-original draft preparation, T.F.; writing-review and editing: B.K., D.R., A.S., and M.B.W.; visualization, T.F., D.R., and A.S.; project administration, T.F., B.K., and A.S. All authors have read and agreed to the published version of the manuscript.

Funding: This research received no external funding.

Acknowledgments: The authors would like to acknowledge the support of B. Werner and H. Reiners in mechanical testing, V. Gutzeit and J. Bartsch in sample preparation, and E. Wessel and D. Grüner for performing the microstructural investigations.

Conflicts of Interest: The authors declare no conflict of interest. The funders had no role in the design of the study; in the collection, analyses, or interpretation of data; in the writing of the manuscript; or in the decision to publish the results.

\section{References}

1. Davies, C.M.; Thomlinson, H.; Hooper, P.A. Fatigue Crack Initiation and Growth Behaviour of 316L Stainless Steel Manufactured Through Selective Laser Melting. In Proceedings of the ASME 2017 Pressure Vessels and Piping Conference, Volume 6A: Materials and Fabrication, Waikoloa, HI, USA, 26 October 2017.

2. Yadollahi, A.; Shamsaei, N.; Thompson, S.M.; Elwany, A.; Bian, L. Effects of building orientation and heat treatment on fatigue behavior of selective laser melted 17-4 PH stainless steel. Int. J. Fatigue 2017, 94, $218-235$. [CrossRef]

3. Zhang, M.; Sun, C.-N.; Zhang, X.; Wei, J.; Hardacre, D.; Li, H. High cycle fatigue and ratcheting interaction of laser powder bed fusion stainless steel 316L: Fracture behaviour and stress-based modelling. Int. J. Fatigue 2019, 121, 252-264.

4. Blinn, B.; Klein, M.; Gläßner, C.; Smaga, M.; Aurich, J.C.; Beck, T. An investigation of the microstructure and fatigue behavior of additively manufactured AISI 316L stainless steel with regard to the influence of heat treatment. Metals 2018, 8, 220. [CrossRef]

5. Spierings, A.B. Fatigue performance of additive manufactured metallic parts. Rapid Prototyp. J. 2013, 19, 88-94. [CrossRef]

6. Meneghetti, G.; Rigon, D.; Gennari, C. An analysis of defects influence on axial fatigue strength of maraging steel specimens produced by additive manufacturing. Int. J. Fatigue 2019, 118, 54-64. [CrossRef]

7. U.S. Federal Aviation Regulations. Advisory circular 25.571-Damage Tolerance and Fatigue Evaluation of Structure. 13 January 2011.

8. Gosselin, S.R.; Simonen, F.A.; Heasler, P.G.; Doctor, S.R. Fatigue Crack Flaw Tolerance in Nuclear Power Plant Piping - A Basis for Improvements to ASME Code Section XI Appendix L (NUREG/CR-6934); U.S. Nuclear Regulatory Commission, Office of Nuclear Regulatory Research: Washington, DC, USA, 2007.

9. ASME. Boiler and Pressure Vessel Code, Section VIII, Division 3, Alternative Rules for Construction of High Pressure Vessels, KD-4: Fracture Mechanics Evaluation. 2019; ISBN 9780791872895.

10. Det Norske Veritas Recommended Practice DNV-RP-C203 Fatigue Design of Offshore Steel Structures. 2011.

11. Riemer, A.; Leuders, S.; Thöne, M.; Richard, H.A.; Tröster, T.; Niendorf, T. On the fatigue crack growth behavior in 316L stainless steel manufactured by selective laser melting. Eng. Fract. Mech. 2014, 120, 15-25. [CrossRef]

12. Riemer, A. Einfluss von Werkstoff, Prozessführung und Wärmebehandlung auf das bruchmechanische Verhalten von Laserstrahlschmelzbauteilen, Forschungsberichte des Direct Manufacturing Research Center; Shaker Verlag: Aachen/Duren, Germany, 2015; band 3; pp. 1-140.

13. Kuhn, B.; Talik, M.; Lopez Barrilao, J.L.; Singheiser, L.; Yamamoto, Y. Development Status of High performance Ferritic (HiperFer) Steels. In Proceedings of the Eighth International Conference on Advances in Materials Technology for Fossil Power Plants, Sheraton Algarve, Portugal, 10-14 October 2016; pp. 1027-1035. 
14. Kuhn, B.; Talik, M.; Barrilao, J.L.; Chen, W.; Ning, J. Microstructure Evolution and Creep Strength of High performance Ferritic (HiperFer) Steels. In Proceedings of the 3rd International ECCC Creep \& Fracture Conference, Rome, Italy, 5-7 May 2014; pp. 502-509.

15. Kuhn, B.; Yamamoto, Y.; Talik, M.; Lopez Barrilao, J. High Performance Ferrite (HiperFer)—A New Alloy Family. In Proceedings of the 4th International ECCC Creep \& Fracture Conference, Duesseldorf, Germany, 10-14 September 2017; pp. 1-10.

16. Kuhn, B.; Talik, M.; Lopez Barrilao, J.; Singheiser, L. Microstructure stability of ferritic-martensitic, austenitic and fully ferritic steels under fluctuating loading conditions. In Proceedings of the 1st 123 HiMat Conference, Sapporo, Japan, 29 June-3 July 2015.

17. Kuhn, B.; Lopez Barrilao, J.; Fischer, T. "Reactive" microstructure, the key to cost-effective, fatigue-resistant high temperature structural materials. In Proceedings of the Joint EPRI-123HiMAT International Conference on Advances in High Temperature Materials, Nagasaki, Japan, 21-24 October 2019; ISBN 13 987-1-62708-271-6.

18. Kuhn, B.; Talik, M.; Fischer, T.; Fan, X.; Yamamoto, Y.; Lopez Barrilao, J. Science and Technology of High Performance Ferritic (HiperFer) Stainless Steels. Metals 2020, 10, 463. [CrossRef]

19. Kuhn, B.; Talik, M.; Zurek, J.; Beck, T.; Quadakkers, W.J.; Singheiser, L.; Hattendorf, H. Development of High Chromium Ferritic Steels Strengthened by Intermetallic Phases. Proceedings of the 7th International Conference on Advances in Materials Technology for Fossil Power Plants, Waikoloa, HI, USA, 22-25 October 2013; ASM International, Materials Park Ohio Industrial Inc.: Cleveland, OH, USA 2013; pp. 1081-1092.

20. Schulz, A.; Beckert, M.; Bietke, D.; Trieglaff, R. Additive Manufacturing-First Approaches to Pore Evaluation. In Proceedings of the 44th MPA-Seminar, Stuttgart, Germany, 17-18 October 2018.

21. ASTM E647-1. Standard Test Method for Measurement of Fatigue Crack Growth Rates; ASTM International: West Conshohocken, PA, USA, 2011; Available online: www.astm.org (accessed on 10 August 2020).

22. Data Sheet VDM Crofer 22 H. Available online: https://www.vdm-metals.com/fileadmin/user_upload/ Downloads/Data_Sheets/Data_Sheet_VDM_Crofer_22_H.pdf (accessed on 10 June 2020).

23. Froitzheim, J.; Meier, G.H.; Niewolak, L.; Ennis, P.J.; Hattendorf, H.; Singheiser, L. Development of high strength ferritic steel for interconnect application in SOFCs. J. Power Sources 2008, 178, 163-173.

24. Hsiao, B.; Kuhn, Z.W.; Chen, D.; Singheiser, L.; Kuo, J.C.; Lin, D.Y. Characterization of Laves phase in Crofer22 H stainless steel. Micron 2015, 74, 59-64. [CrossRef] [PubMed]

25. Talik, M.; Kuhn, B. High Temperature Mechanical Properties of a $17 \mathrm{wt} \% \mathrm{Cr}$ High Performance Ferritic (HiperFer) Steel Strengthened by Intermetallic Laves Phase Particles In Proceedings of the 9th International Charles Parsons Turbine and Generator Conference, Loughborough, UK, 15-17 September 2015.

26. National Board Inspection Code (NBIC). Part-3 National Board Inspection Code; ASME Press: New York, NY, USA, 2011.

27. ASME BPV Code. Section III, Division 1: Rules for Construction of Nuclear Facility Components; ASME Press: New York, NY, USA, 2019.

28. Welding Technology Institute of Australis. (WTIA) publication, TGN-PE-02, Temper Bead Welding, Rev0,1; Welding Technology Institute of Australia: Pymble, Australia, 1 March 2006.

29. ASME BPVC. Section IX-Welding, Brazing, and Fusing Qualifications; ASME Press: New York, NY, USA, 2015.

30. Kuhn, B.; Talik, M.; Niewolak, L.; Zurek, J.; Hattendorf, H.; Ennis, P.J.; Quadakkers, W.J.; Beck, T.; Singheiser, L. Development of high chromium ferritic steels strengthened by intermetallic phases. Mater. Sci. Eng. A 2014, 594, 372-380.

31. Lopez Barrilao, J.; Kuhn, B.; Wessel, E. Microstructure and Intermetallic Particle Evolution in Fully Ferritic Steels. In Proceedings of the 8th International Conference on Advances in Materials Technology for Fossil Power Plants, Algarve, Portugal, 10-14 October 2016; 2016; pp. 1027-1035, ISBN 13: 978-1-62708-131-3.

32. Hsiao, Z.W.; Kuhn, B.; Yang, S.M.; Yang, L.C.; Huang, S.Y.; Singheiser, L.; Kuo, J.C.; Lin, D.Y. The Influence of Deformation on the Precipitation Behavior of a Ferritic Stainless Steel. In Proceedings of the 10th Liége Conference on Materials for Advanced Power Engineering, Schriften des Forschungszentrums Jülich/Energy \& Environment, Liege, Belgium, 14-17 September 2014; Lecomte-Beckers, J., Dedry, O., Oackey, J., Kuhn, B., Eds.; Forschungszentrum Jülich GmbH Zentralbibliothek: Julich, Germany, 2014; Volume 94, pp. 349-358.

33. Lopez Barrilao, J.; Kuhn, B.; Wessel, E. Identification, size classification and evolution of Laves phase precipitates in high chromium, fully ferritic steels. Micron 2017, 101, 221-231. [CrossRef] [PubMed]

34. Lopez Barrilao, J.; Kuhn, B.; Wessel, E.; Talík, M. Microstructure of intermetallic particle strengthened high-chromium fully ferritic steels Mater. Sci. Technol. 2017, 33, 1056-1064. 
35. Lopez Barrilao, J.; Kuhn, B.; Wessel, E. Microstructure evolution and dislocation behaviour in high chromium, fully ferritic steels strengthened by intermetallic Laves phases. Micron 2018, 108, 11-18. [CrossRef] [PubMed]

36. AD 2000 Regelwerk Taschenbuchausgabe 2020; 12. Auflage 2020, Merkblätter Reihe B; Herausgeber: Verband der TÜV e. V. (VdTÜV), Beuth Verlag: Berlin, Germany, 2020; ISBN 13: 9783410299110.

37. Varfolomeyev, I.; Gienko, A.; Krasowsky, A.; Schmitt, W. Development of Weight Functions for Cracks in 3D Bodies; Report T 1/2000 for Fraunhofer IWM: Freiburg, Germany, 2000.

38. IWM VERB. Ver. 8.1 IWM; Fraunhofer-Institut für Werkstoffmechanik: Freiburg, Germany, 2013.

39. Paris, P.C.; Gomez, M.P.; Anderson, W.E. A rational analytic theory of fatigue; In the Trend in Engineering; University of Washington: Seattle, DC, USA, 1961; Volume 13, p. 1.

40. ASME Boiler and Pressure Vessel Code. Section XI Rules for Inservice Inspection of Nuclear Power Plant. Components; ASME Press: New York, NY, USA, 2015.

(C) 2020 by the authors. Licensee MDPI, Basel, Switzerland. This article is an open access article distributed under the terms and conditions of the Creative Commons Attribution (CC BY) license (http://creativecommons.org/licenses/by/4.0/). 